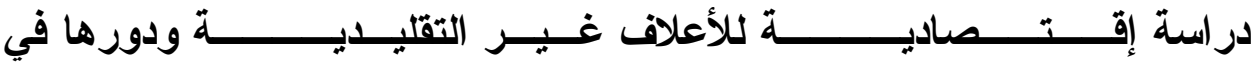

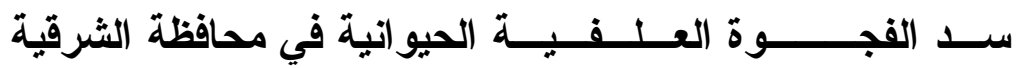

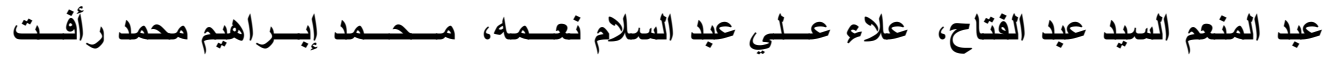

معهُ بحوث الاقتصاد الزراعي ، مركز البحوث الزراعية .

\section{المستخلص}

يعتبر نقص الموارد العلفية من المعوقات الاساسية لتتمية ونطوير الانتاج الحيو اني ، وتشير العديد من الدراسات إلي أن الموازنة العلفية في مصر تعاني

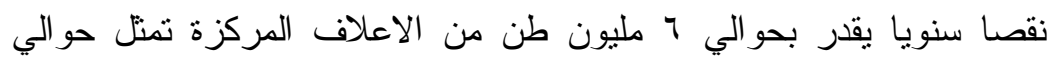

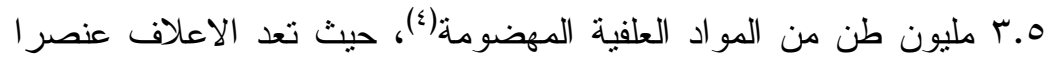

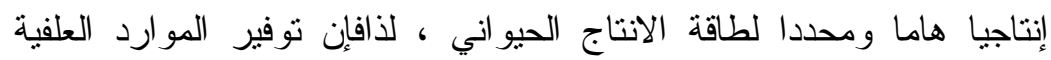

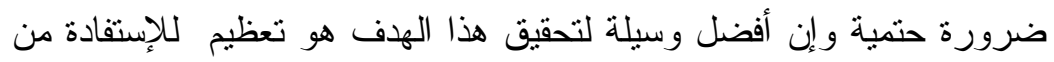
المو اد الغذائية الموجودة في المخلفات الزر اعية كأعلاف حيو انية ومن أهمها

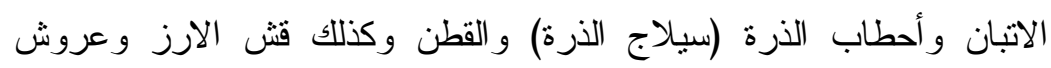

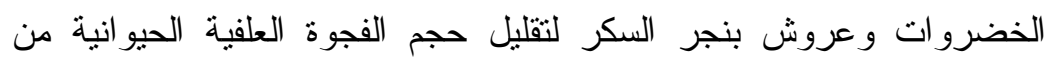
ناحية ، وخفض نسبة التلوث البيئي الناتج من حرق هذه المخلفات الزر اعية

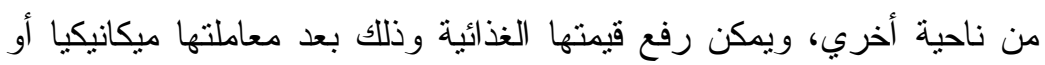
طبيعيا أو كيميائيا أو بيولوجيا حيث تساعد الاعلاف المنزنة غذائيا علي إمداد

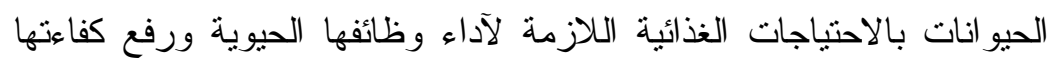

الانتاجية.

\section{مثكلة الدر اسة}

تتمنل في إهدار كميات المخلفات الزراعية لتحويلها إلي أعلاف غير تقليدية حتي بلغت الكميات المستخدمةنحو 0.0 مليون طن من إجمالي كميات المخلفات الزر اعية المتاحة و التي تبلغ حو الي لهي 10

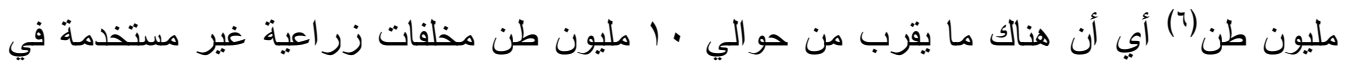

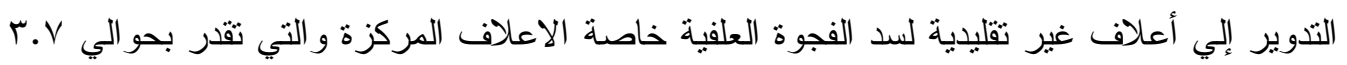

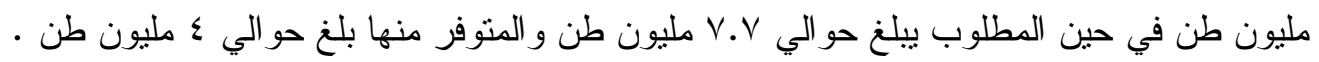

\section{هدف الدراسة}

تهاف الدراسة إلي : (1) دراسة إنتاج الاعلاف من مخلفات بعض المحاصيل المتاح زراعتها بمحافظة الثرقية والتي لم تستغل الاستغلال الامتل (r) دراسة إقتصاديات تدوير المخلفات 
الزر اعية إلي أعلاف غير تقليدية ودور ها في سد الفجوة العلفية بمحافظة الثرقية ـ (r) العمل علي تعظيم الاستفادة من المخلفات الزر اعية في سد الفجوة العلفية بالمحافظة . أهمية الار (سة

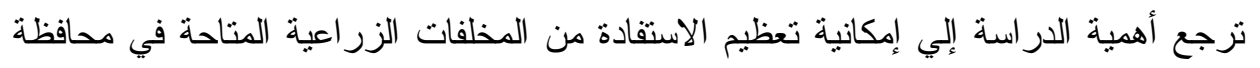

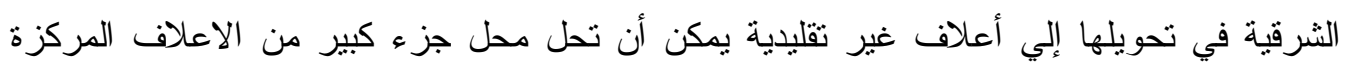
الغالية الثن و المكلفة جدا بالنسبة للمز ارعين وذلك بأقل التكاليف المدكنة مما يساهم في سد الفجوة العلفية بالمحافظة .

\section{مصادر البيانات}

تعتمد الدر اسة على مصدرين رئيسيين للبيانات إولهما : بيانات ثانوية منشورة وغير منشورة

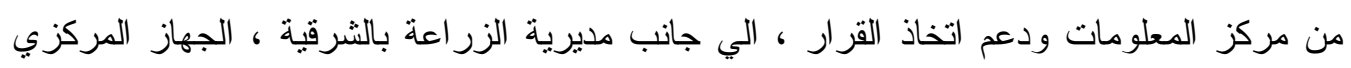

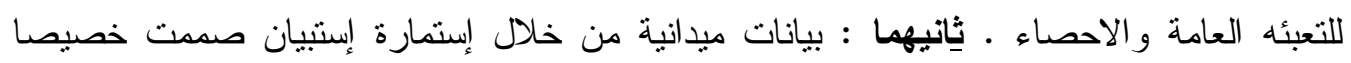

الاسلوب والطريقة البحثية_تعندد الدراسة في تحليل وعرض النتائج على اسلوبيالتحليل

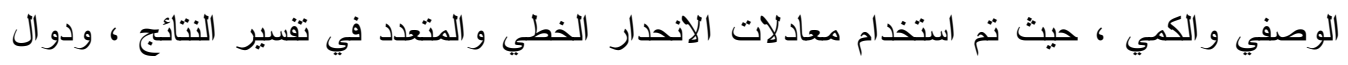
الإنتاج نصف اللوغارتيمية ، بالإضافة إلي إختبار مربع كاي ( Q ل ). وتحليل التباين في إتجاهين .

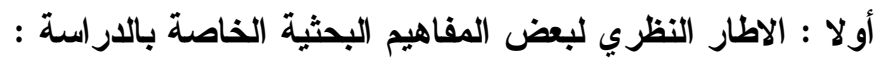
1 - تعريف الفجوة العلفية : يمكن تعريف الفجوة العلفية بأنها الفرق بين ما يتم إنتاجه ( المتاح ) وما يتم إستخدامه ( المطلوب) من الاعلاف المختلفة سواء التقليدية أو غير التقليدية ، وتثير بندية الدراسات إلي أن الموازنة العلفية نعاني نقصا سنويا يعادل هـب مليون طن من المركبات الغذائية

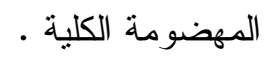
r- كما تعرف الفجوة العلفية بأنها الفرق بين الاحتياجات الغذائية الموصي بها وبين المتاح

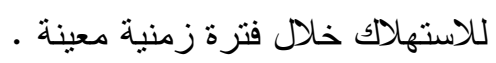

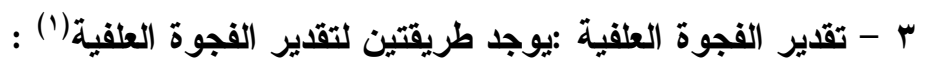

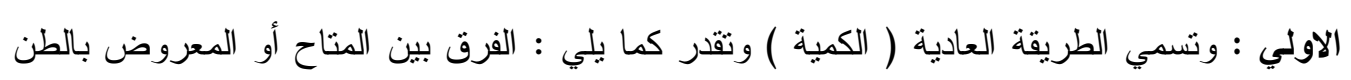

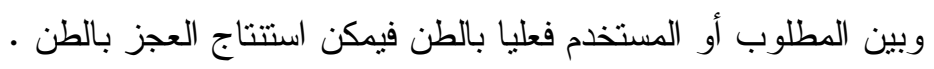

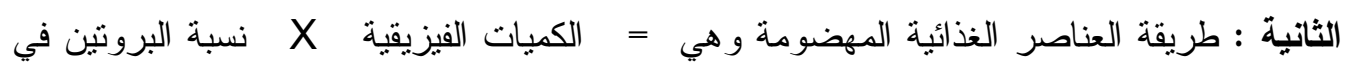
كل عنصر

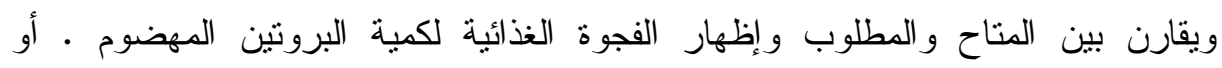
بالكميات الفيزيقية منل السعرات الحرارية لكل عنصر ( معادل النشا ) ومركبات غذائية كلية

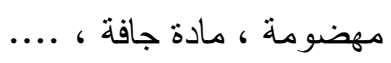

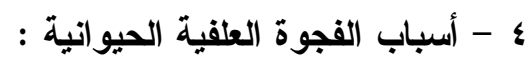

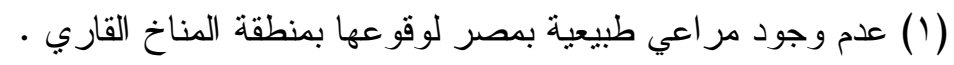
(Y) وجود نتافس شديد بين العلف الحيو اني (البرسيم) و القمح كغذاء للانسان . 


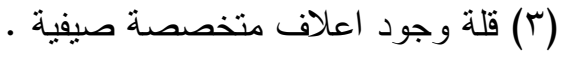

(ا ) الاعتماد علي الإستير اد في توفير مستلزمات العلائق المركزة .

(0) صعوبة توفر النقد الاجنبي اللازم لإستير اد مكونات العلف (الذرة الصفر اء ، فول الصويريا)

$$
\text { و ارتفاع سعر ها. }
$$

(7) وجود بعض مصانع الاعلاف الاهلية والتي تقوم بإستيراد مكونات العلف من الخارج

$$
\text { وتنتخدمها في أغر اض أخري . }
$$

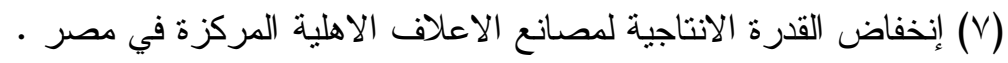

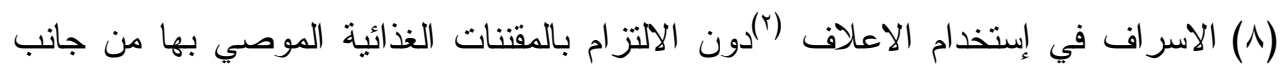

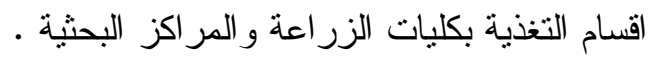

0 - تعريف السيلاج() : السيلاج هو علف أخضر محفوظ بمعزل عن الهواء. و الحفظ يتم بواسطة عمليات التخمر حيث ينتج عن التتفس و التخمرات اللاهو ائية الكحول و الأحماض العضوية التي تزيد من حموضة العلف إلي درجة توقف عو امل التلفكما أن للحفظ مميز اتأخر منها لها أنه يؤدي إلي زيادة نسبة البروتني و الكاروتين و العناصر الغذائية. بجانب أنه يؤدي إلي قتل نقاوي الحشائش الموجودة في نبات العلف مما يقلل من إنتشار ها.كما أنه لوجوده طعم المادة المحفوظة يقل الجزء المرفوض من لئن قبل الحيوان. و الحفظ يتم فيما يعرف بالصومعة أو السيلو وهي إما تكون في صورة حفرة أو حوائط

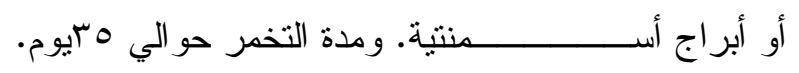

1 - مواصفات السيلاج الجيد :

(1) - نسبة الأمونيا لا تزيد عن ^٪\% دليل علي أن السيلاج جيد والتفاعلات تتم بطريقة جيدة .

وبالتالي إذاز ادت عن 10 \% فيكون حفظ السيلاج ردئ مع زيادة هدم الأحماض الأمينية .

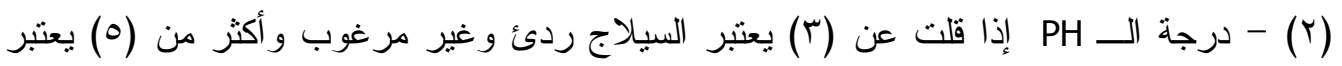

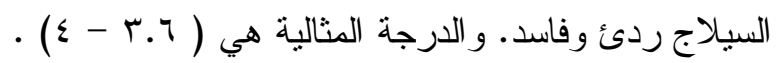
(r) - الحكم علي جودة السيلاج بتفهم العلاقة بين نسبة حامض اللاكتيك بالنسبة إلي الأحماض

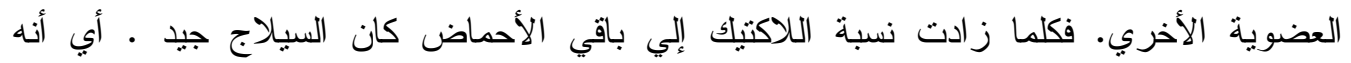
بانخفاض نسبة حمض البيوتزيك و الخليك إلي الأحماض الكلية يكون السيلاج جيدا .

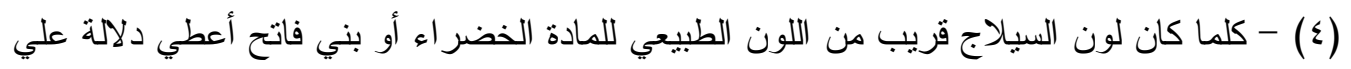

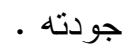

(0) - يمكن الحكم علي السيلاج بأنه جيد في حالة الاحتفاظ بالأوراق و السيقان بحالة جيدة . (7) - كلما كان هناك أثنار طفيفة من حض البي البيوتريك ورائحة الأمونيا أعطي ذلك دلالة علي جودة أ - ضرورة إستبعاد الهو اء و عدم وجود الأوكسجين.

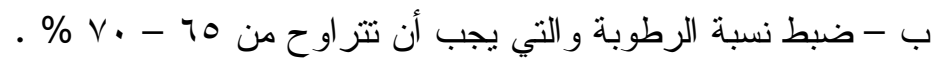

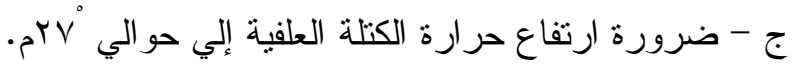


د - لابد من توفر مقدار كبير من الكربو هيدرات القابلة للتحلل بواسطة بكتيريا حمض اللاكتيك.

هـ - ضرورة الكبس الجيد في المكمورة واستخدام غطاء جيد محكم لهنع دخول الهو اء. ثانيا : الوضع الحالي للفجوة العلفية الحيوانية في مصر : فيما يلي نوضيح لعدد الحيوانات في مصر مقدر البوحدات الحيو انية بصورة تقريبية والاحتياجات الغذائية كمركبات غذائية مهضومة ، وكذلك أنو اع المو اد العلفية وبيان المتاح منها و المتوفر والعجز ( الفجوة ) أو الزيادة في مصر : تشير بيانات جدول رقم (1) عدد الحيوانات المزرعية بالمليون رأس في مصر ووحداتهالحيو انية

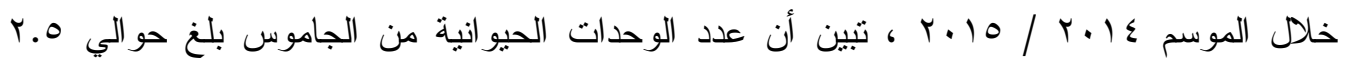

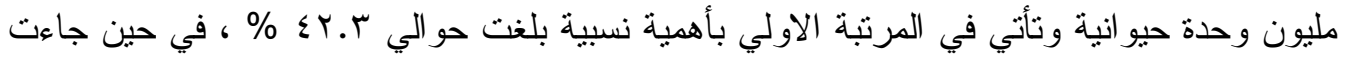
الابقار في المرنبة الثانية حيث بلغت عدد الوحدات الحيو انية منها حو الي ع ع. مليون وحدة حيو انية بأهمية نسبية بلغت حوالي 9.9 r \% ، في حين جاءت الاغنام و الماعز في المرنبة الثالثة و الرابعة

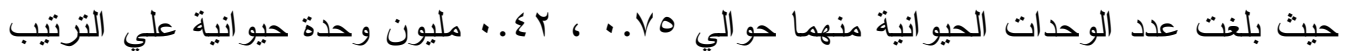

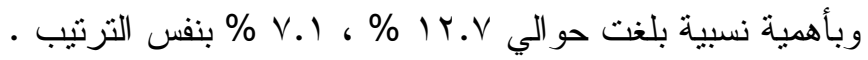

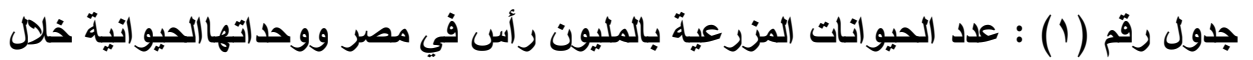

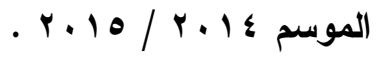

\begin{tabular}{|c|c|c|c|c|c|}
\hline الاهمية النسبية & عدد الوحدات الحيو انية & التحويل (†) معامل & العدد (') & اسم الحيو ان & r \\
\hline$\varepsilon r . r$ & r.o & 1 & r.o & جاموس & 1 \\
\hline TV.q & T.TE &..$\wedge$ & r.A & أبقار & r \\
\hline IT.V & $\therefore$. &.$r$ & r.o & أغنام & $r$ \\
\hline v. & . . &.$r$ & $1 . \varepsilon$ & ماعز & $\varepsilon$ \\
\hline $1 \ldots$ & 0.91 & \multicolumn{4}{|c|}{ الاجمالي } \\
\hline
\end{tabular}

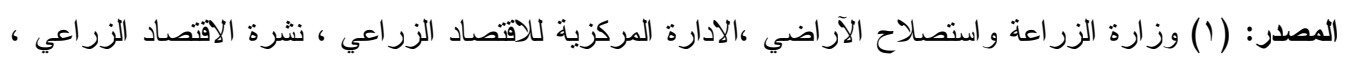

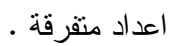
(Y) ابر اهيم سليمان (دكتور) ، احمد مشهور (دكتور) : كتاب اساسيات اقتصاديات و وادارة مزارع الانتاج الحيو اني

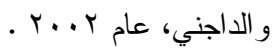

كما تثنير بيانات جدول رقم (r) إلي بعض المواد العلفية المتاحة في محافظة الثرقية

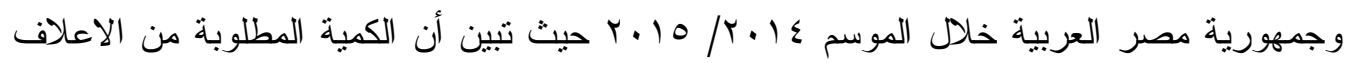

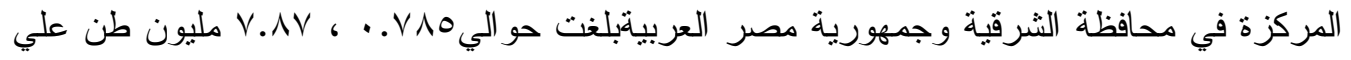

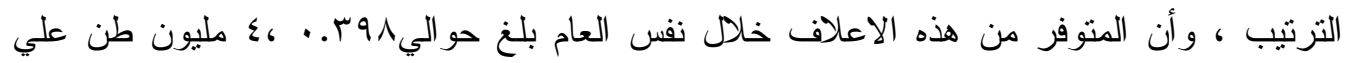

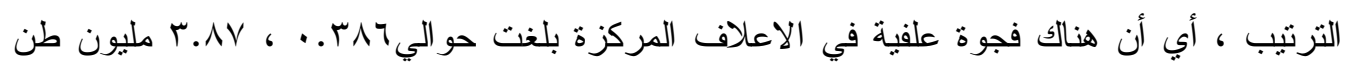

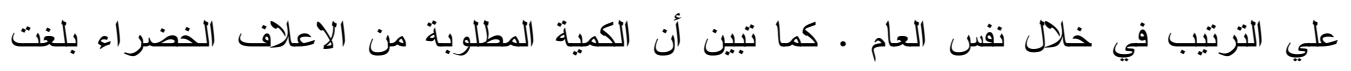
r 


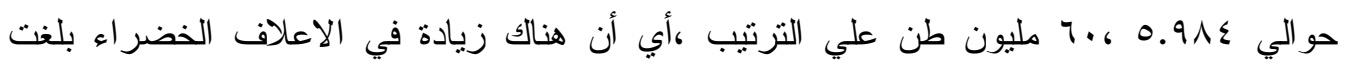

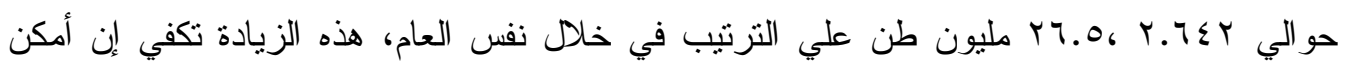

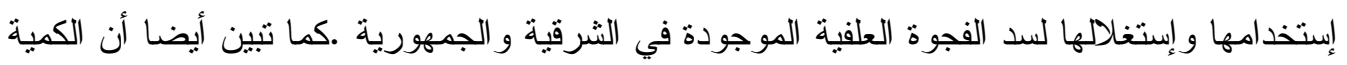

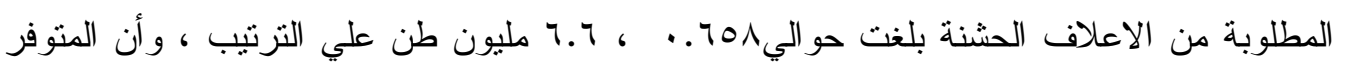

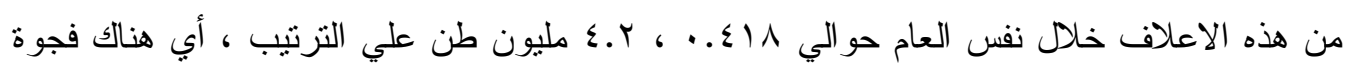

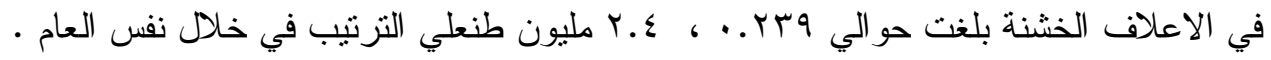

جدول رقم (r) : المو اد العلفية الحيوانية بالمليون طن المتاحة في محافظة الثرقية وجمهورية

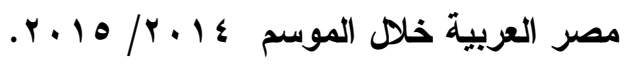

\begin{tabular}{|c|c|c|c|c|c|c|c|}
\hline \multicolumn{2}{|c|}{ الفجوة أو الزيادة } & \multicolumn{2}{|c|}{ المتوفر } & \multicolumn{2}{|c|}{ الكمبة } & \multirow[t]{2}{*}{ المو اد العلفية } & \multirow[t]{2}{*}{ 5 } \\
\hline الجمهورية & الثرقية & الجمهورية & الشرقية & الجمهورية & الثرقية & & \\
\hline r.AV - & - rNT - & $\varepsilon$ &..$r 91$ & V.AV & $\therefore$ V10 & أعلاف مركزة & 1 \\
\hline r..० & $r . T \leq r$ & 7. & $0.91 \varepsilon$ & rT.01 & $r . r \leqslant r$ & أعلاف خضر اء & r \\
\hline T.乏 - & . .rrq - & $\varepsilon . r$ & ..ह1^ & 7.7 &. .701 & أعلاف خشنة & $r$ \\
\hline
\end{tabular}

المصدر :(1) ابر اهيم سليمان (دكتور) ، احمد مشهور (دكتور) : كتاب اساسيات اقتصاديات و ادارة مزارع الانتاج

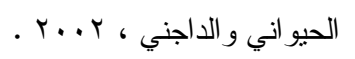

(r) وز ارة الزر اعة واستصلاح الار اضي ، قطاع الثئون الاقتصادية ، نشرة الاحصاءات الزراعية ، بياتات رسمية ،

ثالثــــا : عدد الحيوانات المزرعية ووحداتها الحيوانية في محافظة الشرقية : اعداد الحيوانات المزرعية الحية : نتشير بيانات جدول رقم (ץ) إلي أن عدد الحيو انات المزرعية

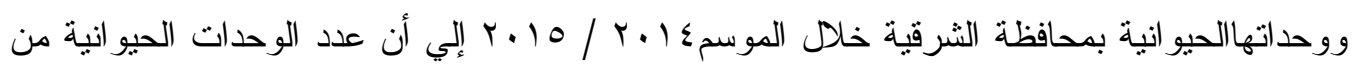

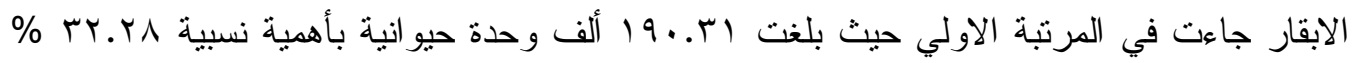
من إجمالي عدد الوحدات الحيو انية ، وجاءت عدد الوحدات الحيو انية من الجاموس في المرنبة الثانية

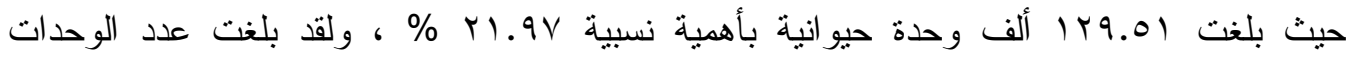

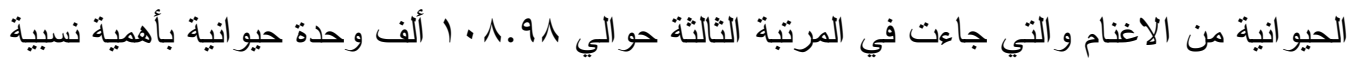

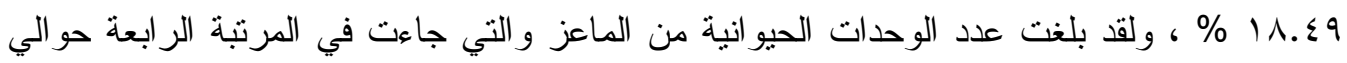

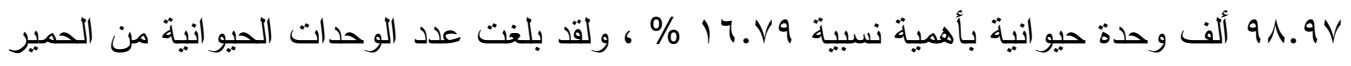

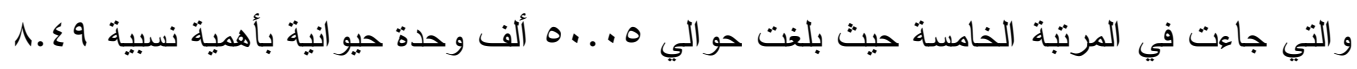
\% ، و أخير ا بلغت عدد الوحدات الحيو انية من الحيوانات الاخري ( تشمل الابل والطلائق و البغال

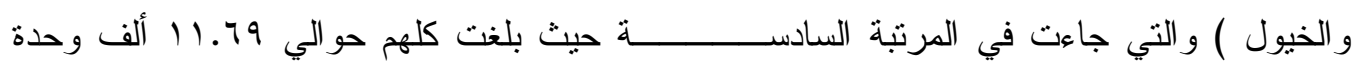




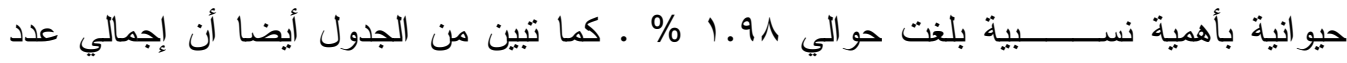

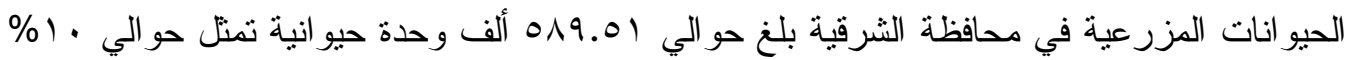

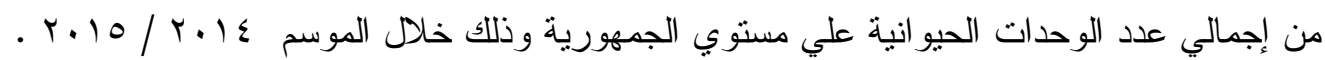

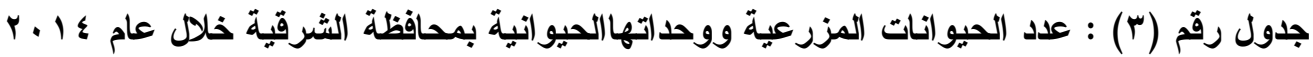

\begin{tabular}{|c|c|c|c|c|c|}
\hline الاهمية النسبية & ( عدالالف الوحدات الحيو انية & معامل التحويل (r) & (بالألف رأس) (1) & أسم الحيو انات & b \\
\hline rt.rA & $|9 . . T|$ & $\cdot . \wedge$ & rrV.Aq & الابقار & 1 \\
\hline r). $9 v$ & $1 \times 9.01$ & 1 & $1 \times 9.01$ & الجاموس & r \\
\hline $1 \wedge . \leqslant 9$ & 1.1 .91 &.$r$ & & الاغنام & r \\
\hline 17.89 & $9 \wedge .9 \vee$ & r. & rrq.q1 & الماعز & $\varepsilon$ \\
\hline$\wedge . \leqslant 9$ & $0 . .00$ &. .00 & $91 . .1$ & الحمير & 0 \\
\hline. .97 & 0.70 & 1.1 & r.lక & الابل & 7 \\
\hline. .00 & r.r &.$\wedge$ & $\varepsilon . \cdot \varepsilon$ & الطلائق & v \\
\hline..$\mu V$ & r.r. & .00 & $\varepsilon . .1$ & البغال & $\wedge$ \\
\hline .1 &. .7 & .00 & $1 . .9$ & الخيول & 9 \\
\hline $1 \ldots$ & $0 \wedge 9.01$ & \multicolumn{4}{|c|}{ الاجمالي } \\
\hline
\end{tabular}

المصدر : ( () مديرية الزر اعة بالثرقية ، قسم الانتاج الحيو اني ، قسم الاحصاء ، سجلات رسمية ، بيانات غير منشورة . $r .1 \leq 6$ (Y) ابر اهيم سليمان (دكتور)، الحمد مشهور (دكتور): كتاب اساسيات اقتصاديات وادارة مزارع الانتاج الحيواني

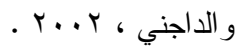

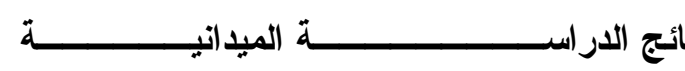

أولا : عينة الاراسة الميدانية: أ : توصيف وإختيار عينة الدراسة الميدانية : تمشيا مع مشكلة الدراسة وتحقيقا لأهدافها فقــد تـم

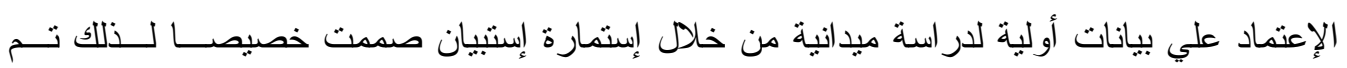

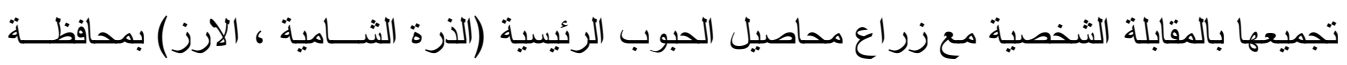

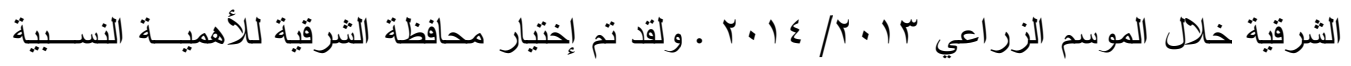

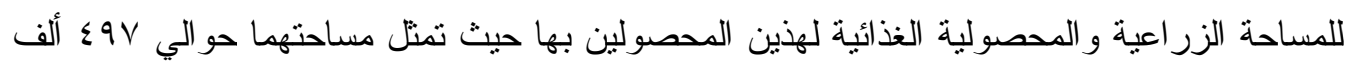
فدان و هي تمنل حو الي وه \% من إجمالي المساحة المحصولية بمحافظة الثرقية و التي تنلغ حــو الي

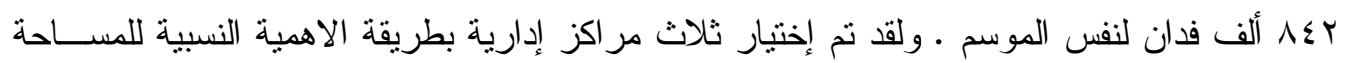

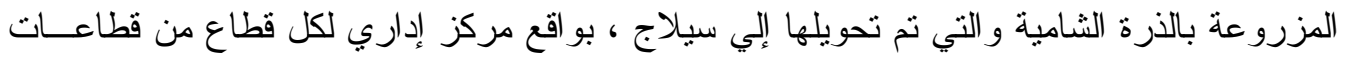

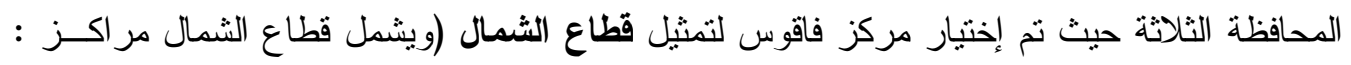

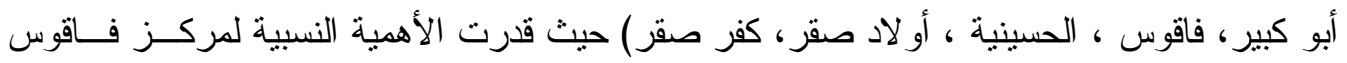




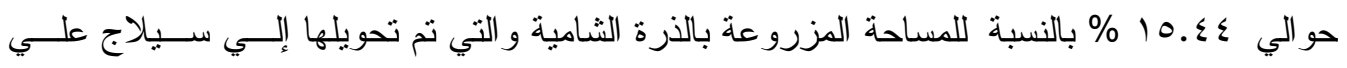

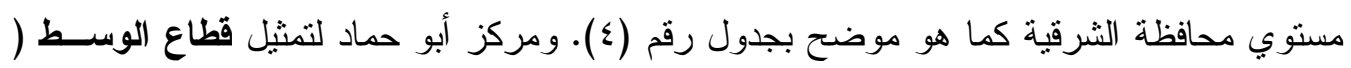

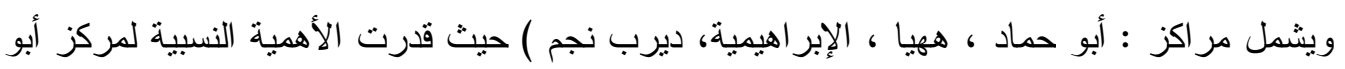

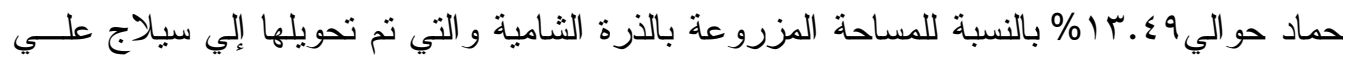

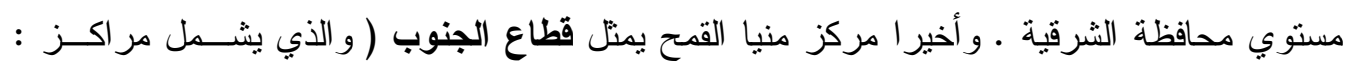

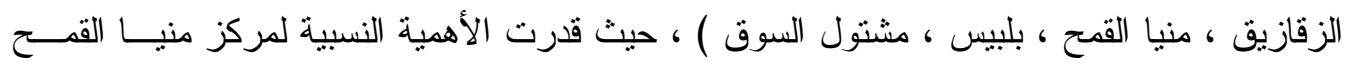

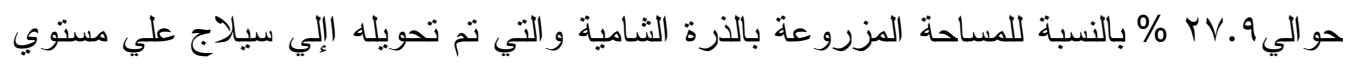

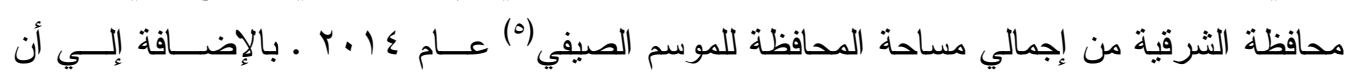

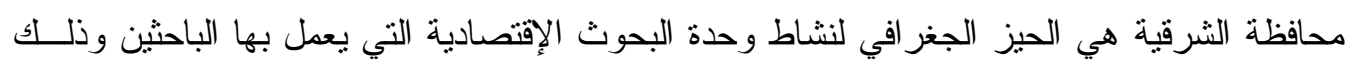

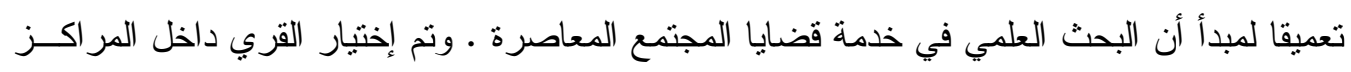

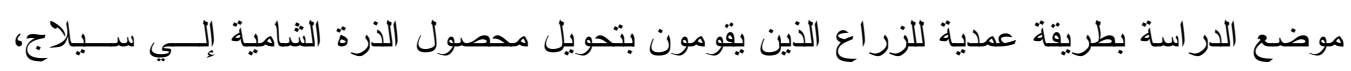
وتحويل قش الارز إلي قش ارز معالج و الذي يستخدم كغذاء للحيو انات. حيث تم إختيار قرية ( منشأة

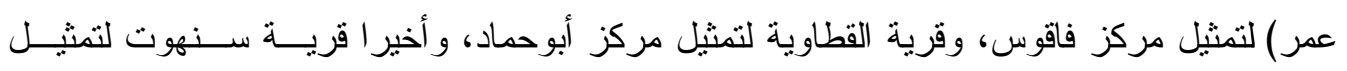

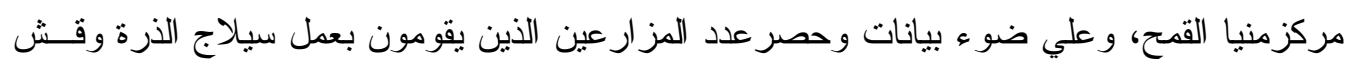

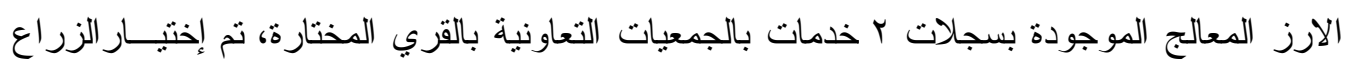

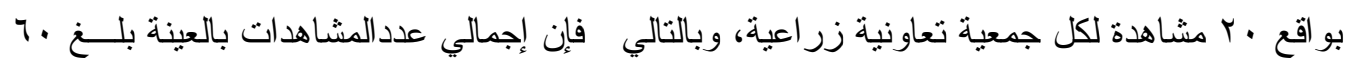

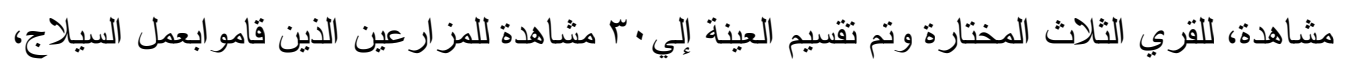

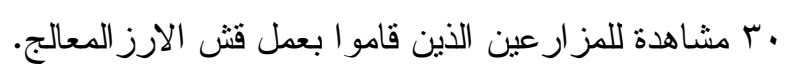

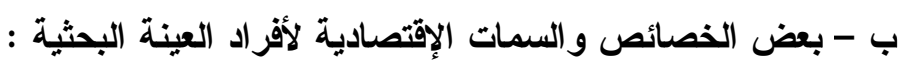

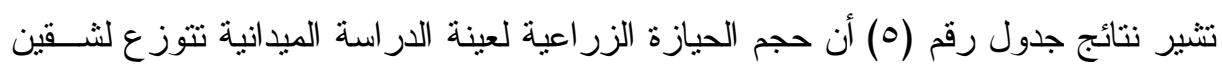

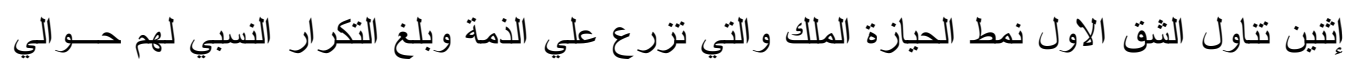

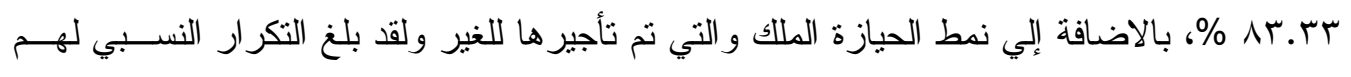

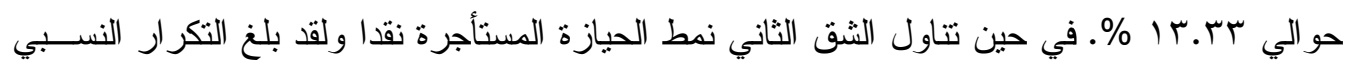

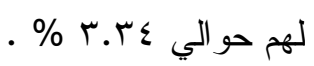

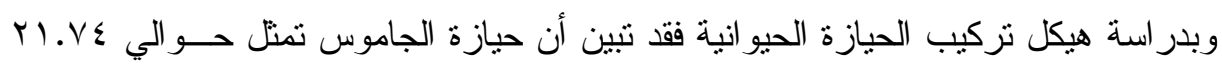

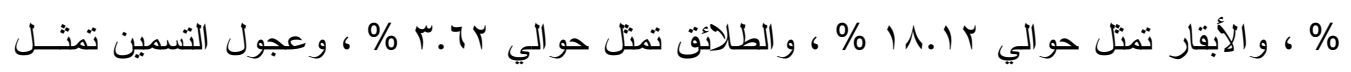

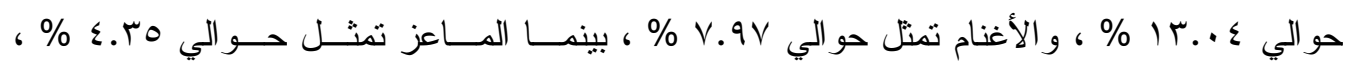

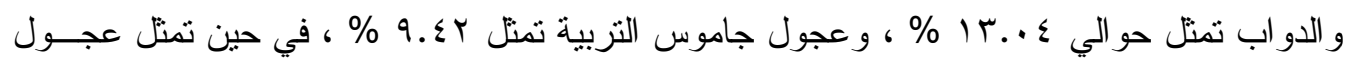

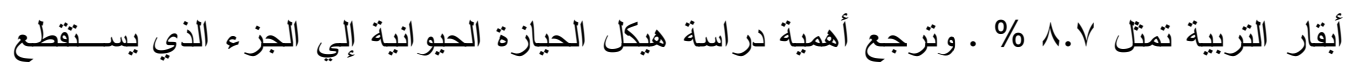

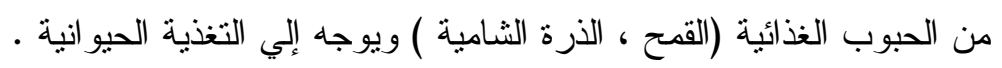




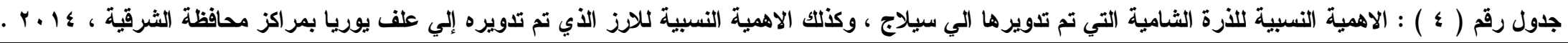

\begin{tabular}{|c|c|c|c|c|c|c|c|c|c|}
\hline \multicolumn{6}{|c|}{ 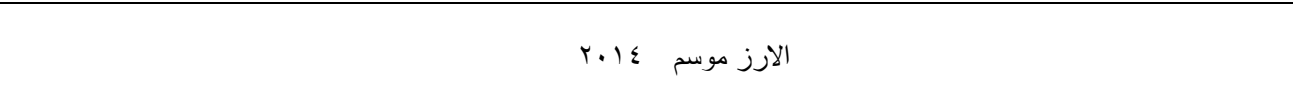 } & \multicolumn{4}{|c|}{ الذرة الثامية بالكوز التي تم عملها سيلاج موسم ع ا بr } \\
\hline \multicolumn{3}{|c|}{ علف يوريا } & \multirow{2}{*}{ ترتيب \% للسساحة } & \multirow[b]{2}{*}{$\%$} & \multirow[b]{2}{*}{ مساحة الارز } & \multirow[b]{2}{*}{$\%$} & \multirow[b]{2}{*}{ مساحة الذرة بالفدان } & \multirow[b]{2}{*}{ المركز } & \multirow[b]{2}{*}{ مسلسل } \\
\hline ترتيب \% لأفنة & $\%$ & عدد الاففنة & & & & & & & \\
\hline 1 & 40.93 & 711 & 3 & 10.34 & 25428 & 27.9 & 1200 & منيا القمح & 1 \\
\hline 3 & 11.51 & 200 & 12 & 3.15 & 7753 & 15.44 & 664 & فاقوس & 2 \\
\hline 7 & 4.43 & 77 & 10 & 4.25 & 10453 & 13.49 & 580 & ابو حماد & 3 \\
\hline 8 & 3.16 & 55 & 15 & 1.06 & 2599 & 10.46 & 450 & بلبيس & 4 \\
\hline 2 & 21.36 & 371 & 11 & 3.76 & 9254 & 10.09 & 434 & هييا & 5 \\
\hline 4 & 6.91 & 120 & 13 & 2.15 & 5285 & 8.95 & 385 & الاببر اهيمية & 6 \\
\hline 5 & 5.75 & 100 & 14 & 1.80 & 4432 & 5.46 & 235 & الزقازيق & 7 \\
\hline \multirow[t]{5}{*}{6} & 5.75 & 100 & 4 & 9.75 & 23972 & 3.65 & 157 & ل ديرب نجم & 8 \\
\hline & 0 & 0 & 8 & 6.59 & 16213 & 3.35 & 144 & كفر صقر & 9 \\
\hline & 0 & 0 & 9 & 5.11 & 12567 & 1.21 & 52 & مشنول & 10 \\
\hline & 0 & 0 & 6 & 8.04 & 19785 & 0 & 0 & اول لاد صقر & 11 \\
\hline & 0 & 0 & 2 & 12.71 & 31255 & 0 & 0 & ابو كبير & 12 \\
\hline \multirow[t]{4}{*}{9} & 0.17 & 3 & 1 & 14.96 & 36800 & 0 & 0 & الحسينية & 13 \\
\hline & 0 & 0 & 5 & 8.75 & 21511 & 0 & 0 & اصلاح زر اعي & \\
\hline & 0 & 0 & 7 & 7.13 & 17547 & 0 & 0 & شركات & \\
\hline & 100 & 1737 & & 100 & 245854 & 100 & 4301 & \multicolumn{2}{|c|}{ اجمالي المحافظة } \\
\hline
\end{tabular}

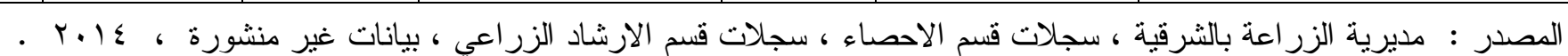


جدول رقم (0) : بعض الخصائص والسمات الإقتصادية لمبحوثي عينة الدراسة الميدانية بمحافظة

\begin{tabular}{|c|c|c|c|c|c|c|c|}
\hline الألهمية & الوحدة & صائص و السمات & & النسبية & الوحد & \multicolumn{2}{|c|}{ الخصائص والسمات } \\
\hline 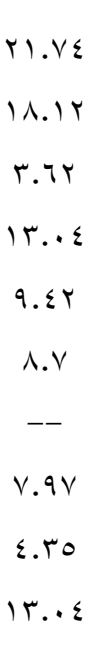 & $\begin{array}{l}\% \\
\% \\
\% \\
\% \\
\% \\
\% \\
\% \\
\% \\
\% \\
\%\end{array}$ & 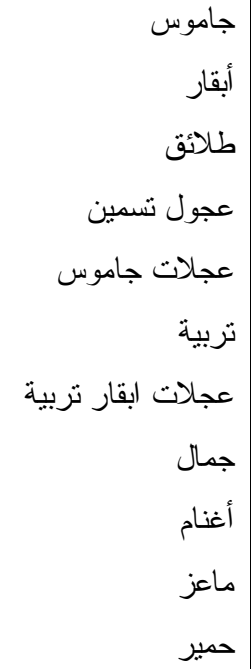 & 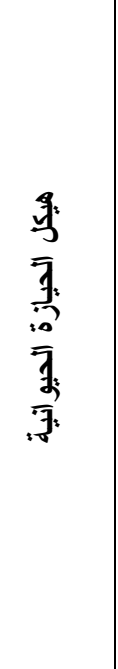 & $\begin{array}{l}r . r \leq \\
-- \\
r . r \leq \\
1 . .\end{array}$ & $\begin{array}{l}\% \\
\% \\
\% \\
\%\end{array}$ & 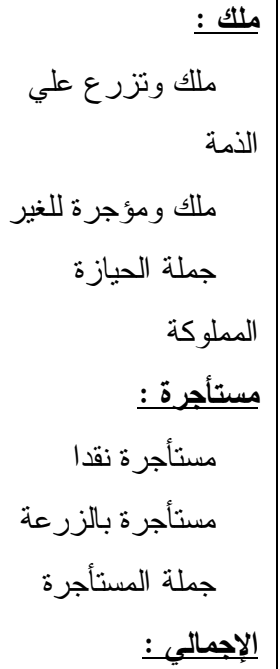 & 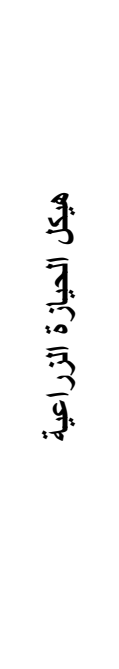 \\
\hline 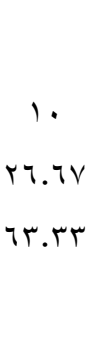 & $\begin{array}{l}\% \\
\% \\
\%\end{array}$ & 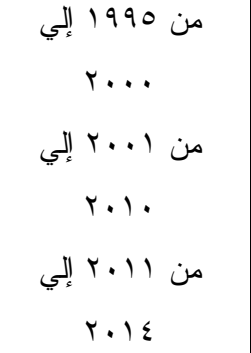 & 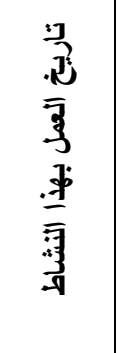 & $\begin{array}{l}1.19 \\
r 1.19 \\
r 0.00 \\
10.07 \\
1.19\end{array}$ & $\begin{array}{l}\% \\
\% \\
\% \\
\% \\
\%\end{array}$ & 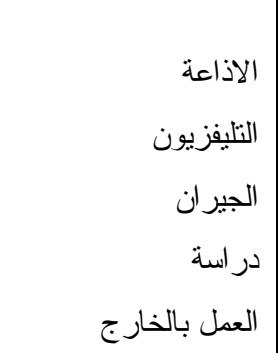 & 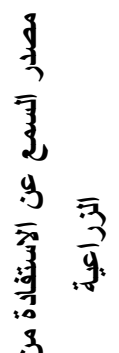 \\
\hline $\begin{array}{l}\text { VT.TV } \\
\text { r. } \\
\text { r.tr }\end{array}$ & $\begin{array}{l}\% \\
\% \\
\%\end{array}$ & أقل من ب سنو ات - من سنو من ه سنو ات & 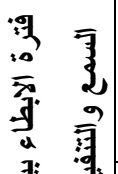 & $\begin{array}{l}r . r \\
1 . .\end{array}$ & $\begin{array}{l}\% \\
\%\end{array}$ & $\begin{array}{r}\text { العمل بالقطاع الزر اعي } \\
\text { الاجمالي }\end{array}$ & 牙 \\
\hline $1 \ldots$ & $\%$ & & & & & & .? \\
\hline $\begin{array}{l}r . . T V \\
V 4.7 V \\
r . .7 V \\
V . r\end{array}$ & $\begin{array}{l}\% \\
\% \\
\% \\
\%\end{array}$ & 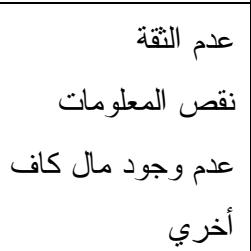 & 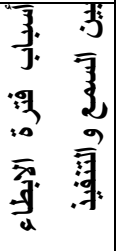 & $\begin{array}{l}\text { \&.rT } \\
\varepsilon \pi .4 V\end{array}$ & $\begin{array}{l}\% \\
\% \\
\%\end{array}$ & 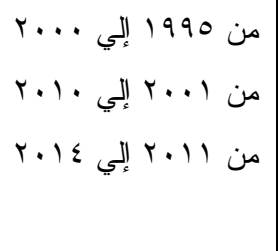 & 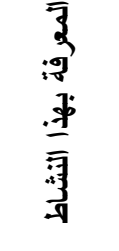 \\
\hline
\end{tabular}

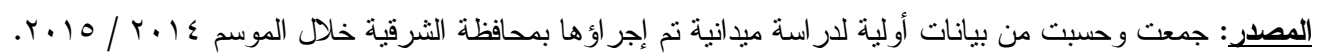

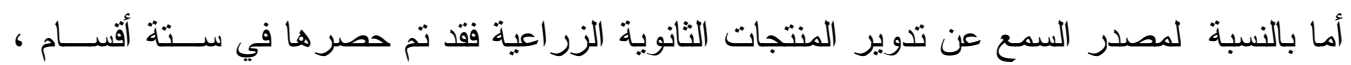

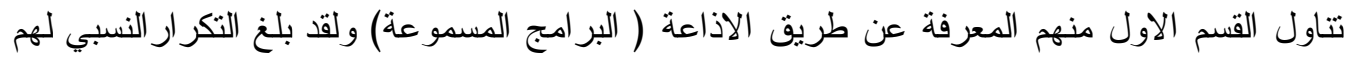

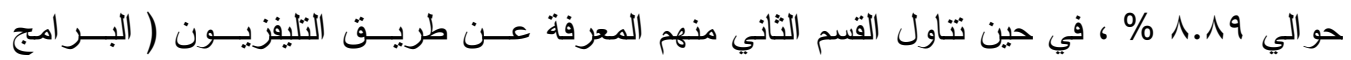

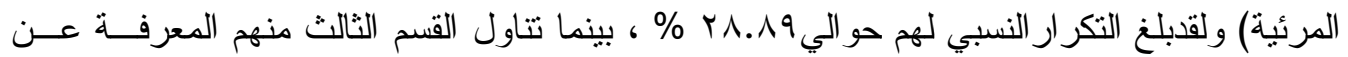

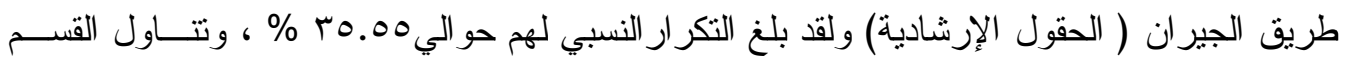




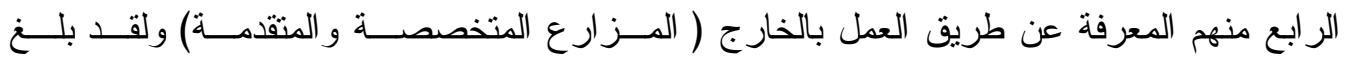

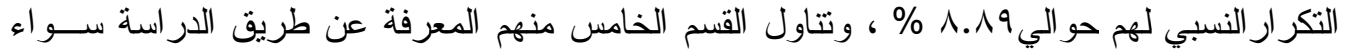

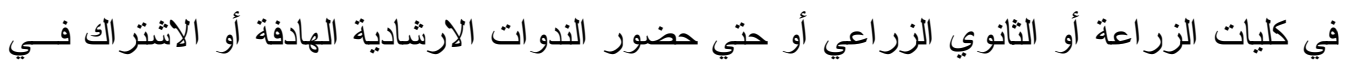
بعض الدور ات التدرييية المتخصصة ولقد بلغ التكر ار النسبي لهم حوالي 10.07 \% ، و وأخير ا تتــاول

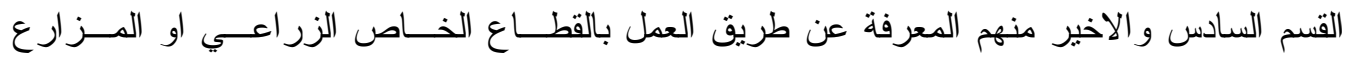

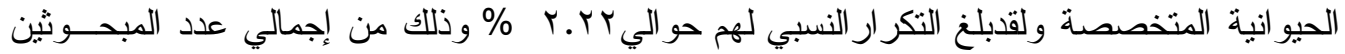
بعينة الدر اسة .

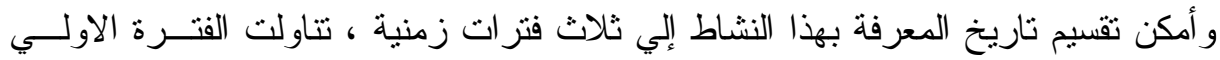

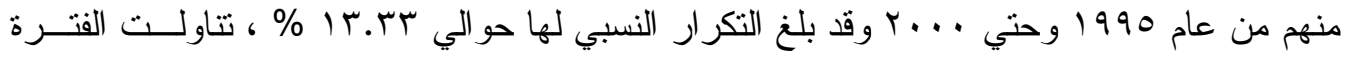

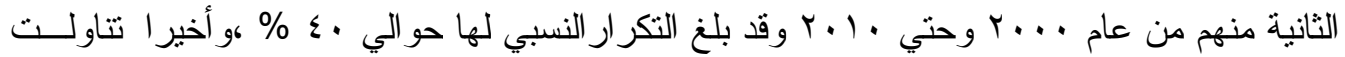

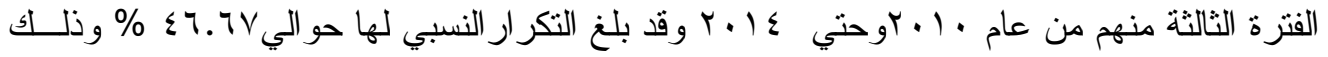

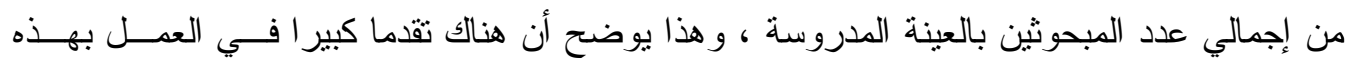

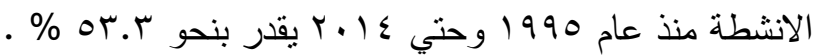

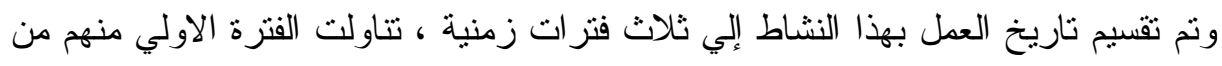

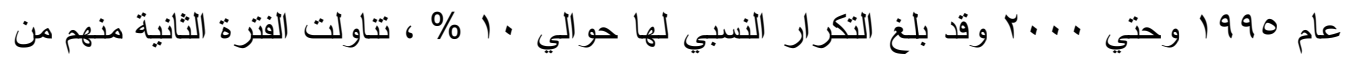

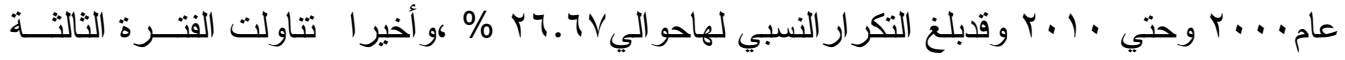

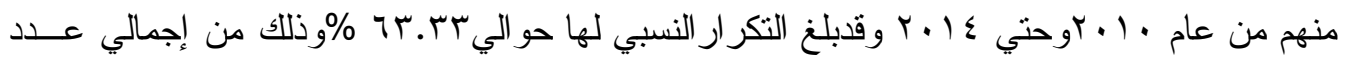

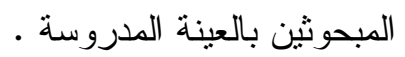

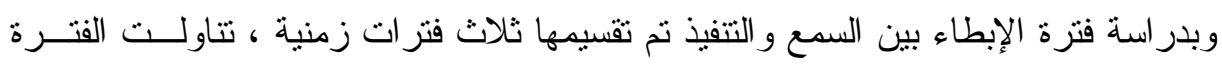

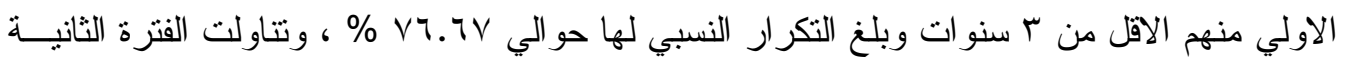

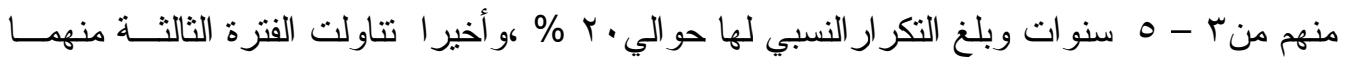

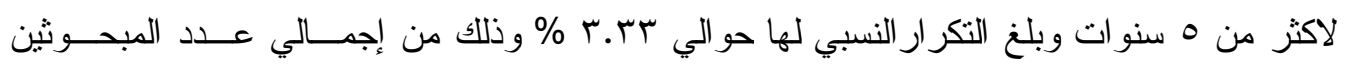
بالعينة المدروسة من ماه وبالاتشارة إلي أسباب فترة الإبطاء بين السمع و التتفيذ نم تقسيمها لثناث عناصر ، تتــاول العنصـر

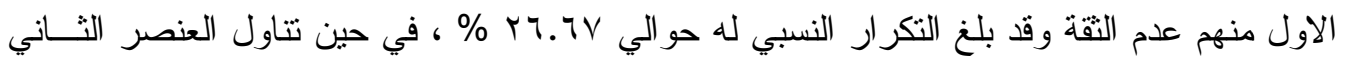

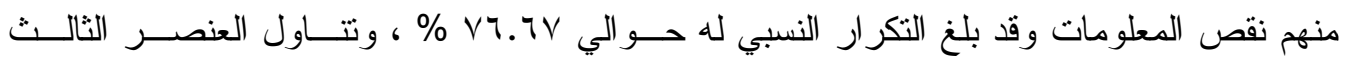

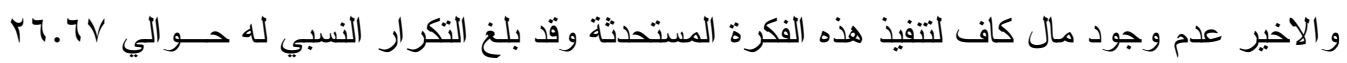
\% وذلك من إجمالي عدد المبحوثين بالعينة المدروسة. ج- أنماط تصنيع الأرة الشامية وقش الاردئ يوجد أكثر من نمط لتصنيع الذرة الثامية وقش الارز ، وفي الأورت الذي يقتصر تصنيع

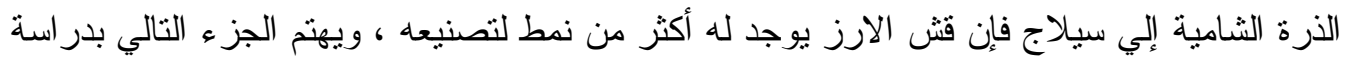
أنماط تصنيع الذرة وفش الارز : 
تشير نتائج جدول رقم (ך) عدد المزارعين الذين يقومون بعمل السيلاج وقش الارز

المعامل و الكميات المستخدمة من النواتج الثانوية الزر اعية بمحافظة الثرقية خلال الفترة من م ...

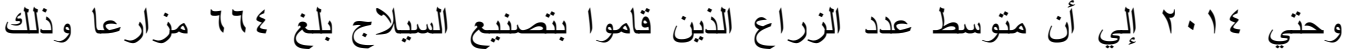

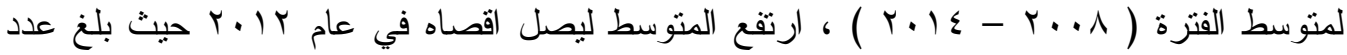

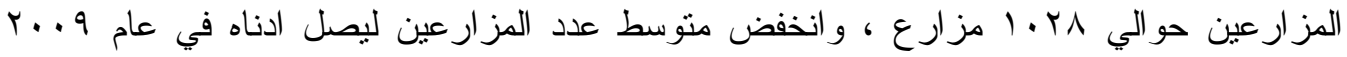

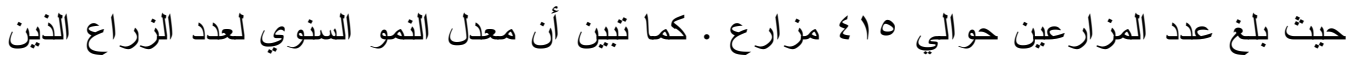

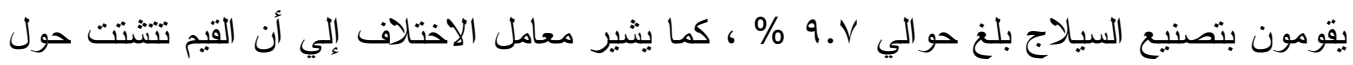

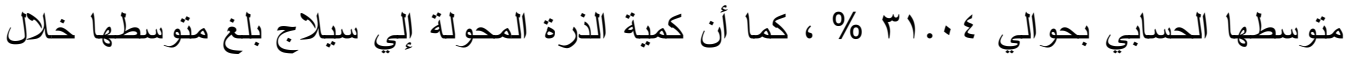

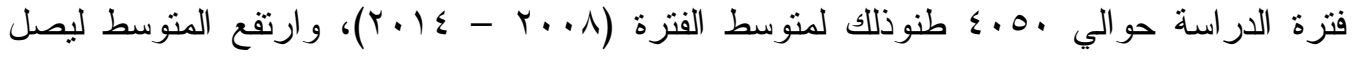

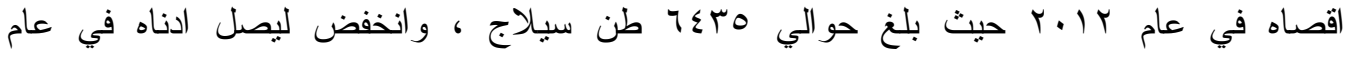

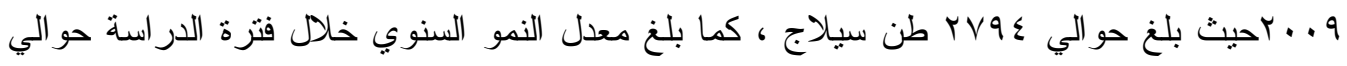

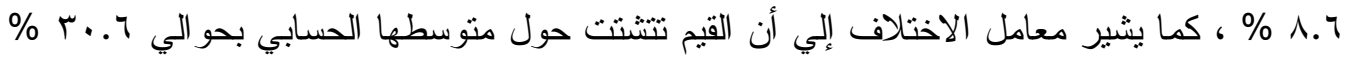

كما تشير بيانات نفس الجدول (T) إلي أن متوسط عدد الزراع الذين قامو ابعمل كومات

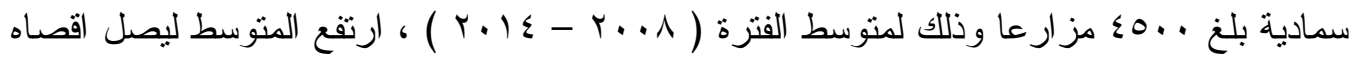

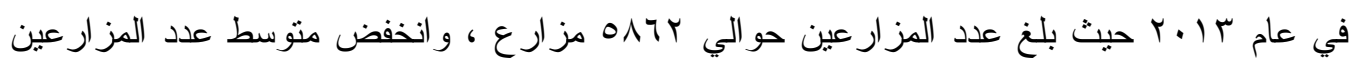

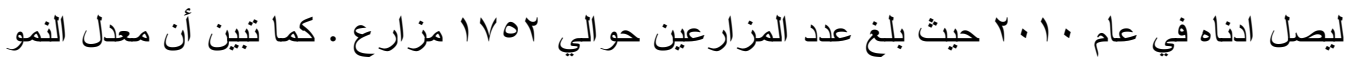

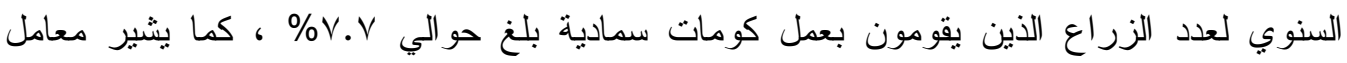

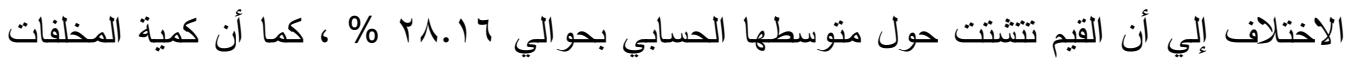

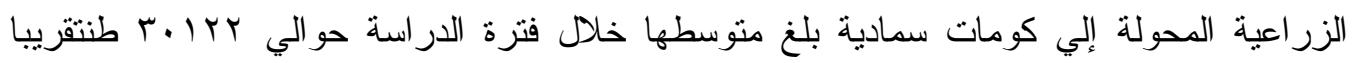

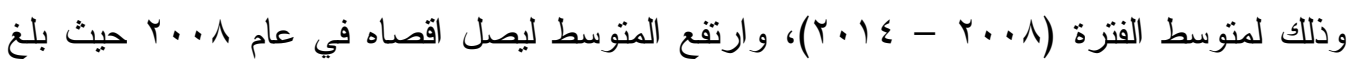

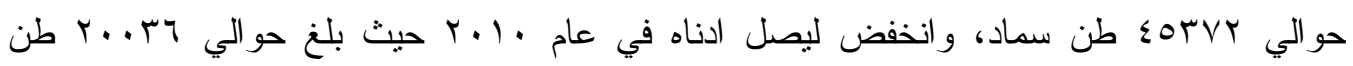

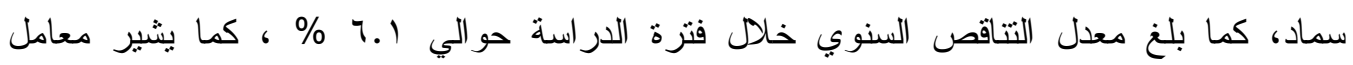

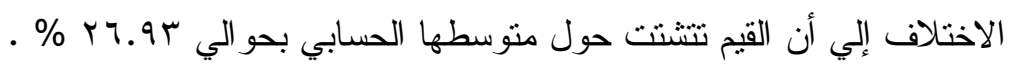

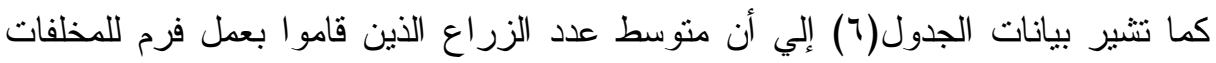

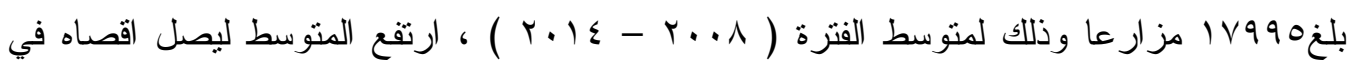

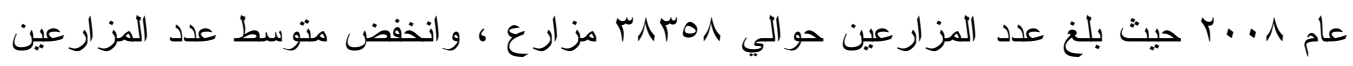

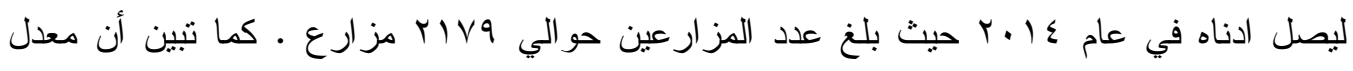

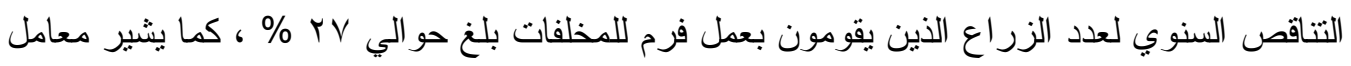

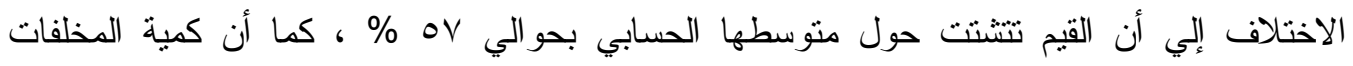

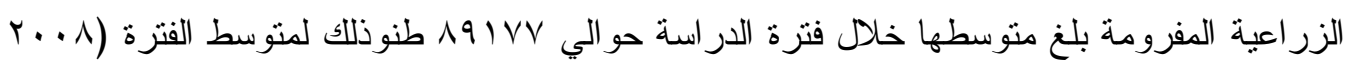

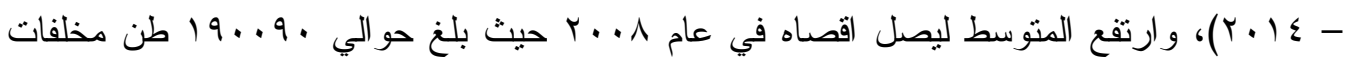

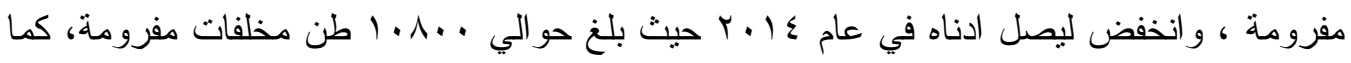


بلغ معدل التتاقص السنوي خلال فترة الدر اسة حو الي V. Y \% \% ، كما يشير معامل الاختلاف إلي أن

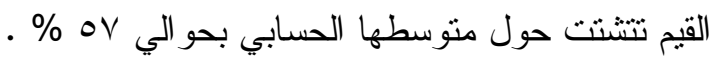

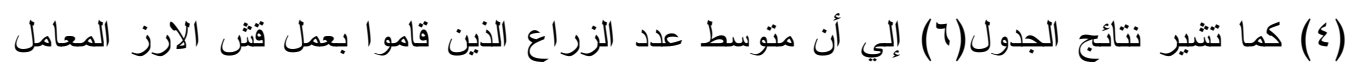

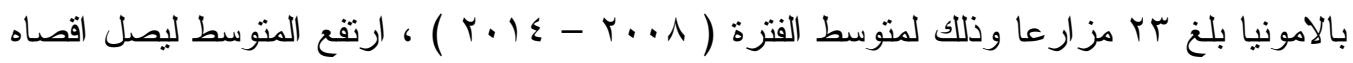

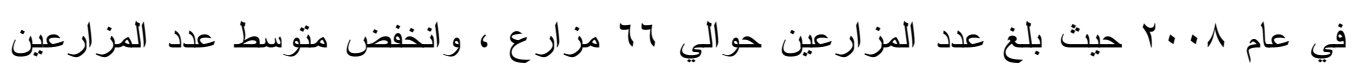

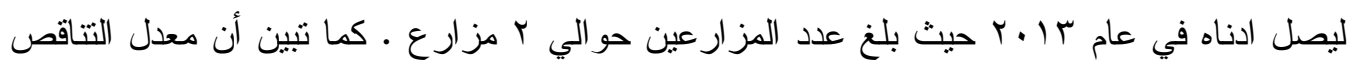

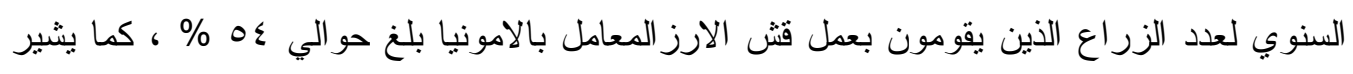

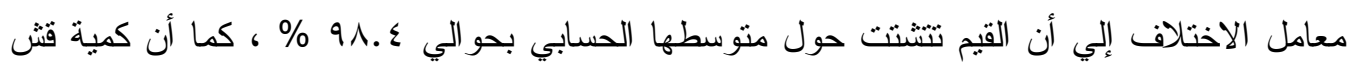

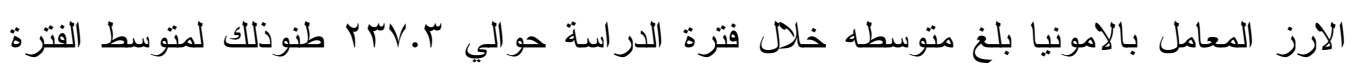

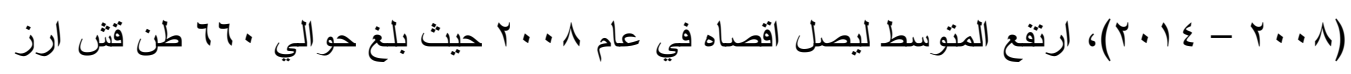

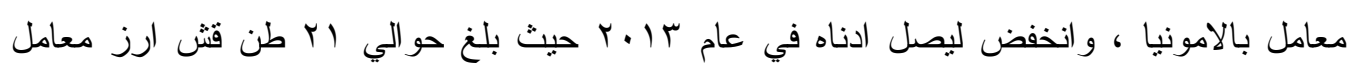

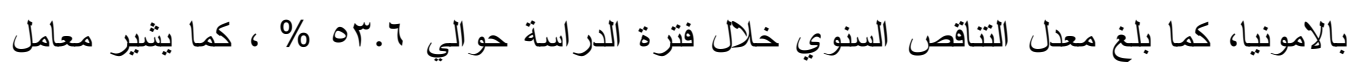

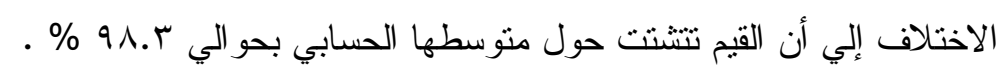

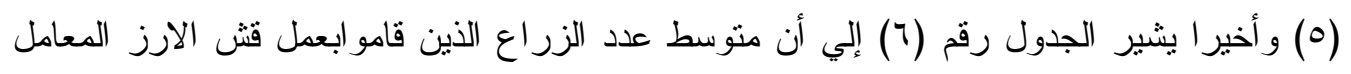

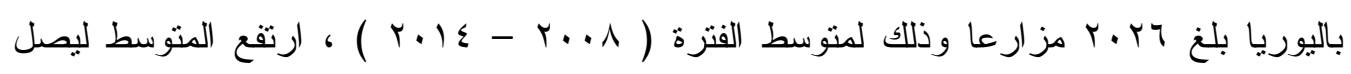

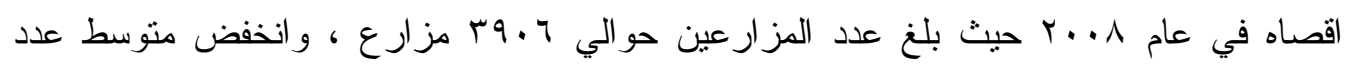

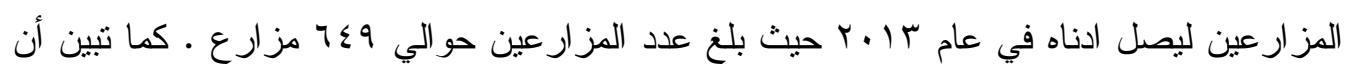

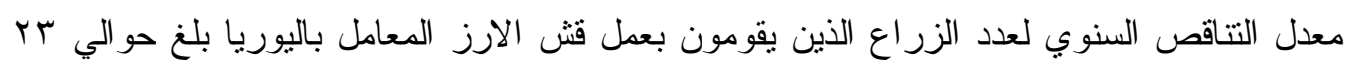

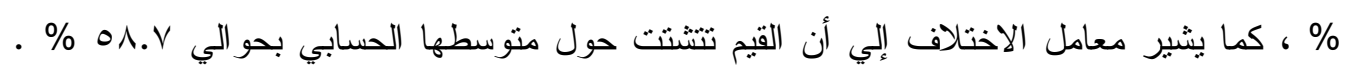

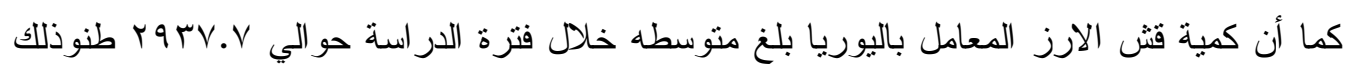

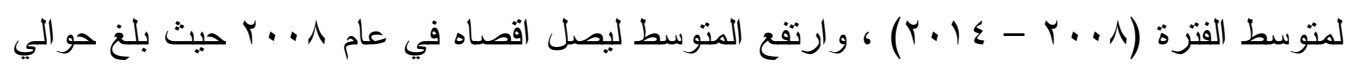

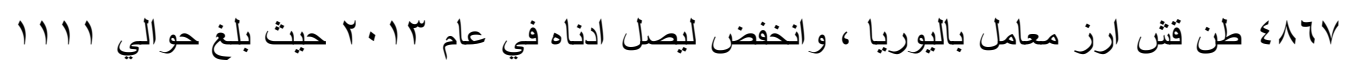

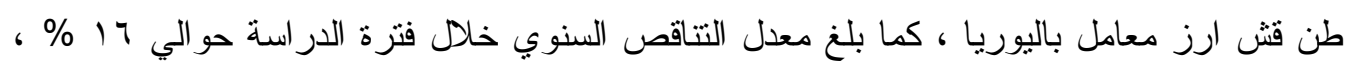

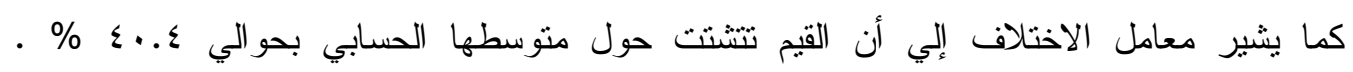


جدول (†) : عدد المزارعين الذين يقومون بعمل السيلاج وقش الارز المعامل باليوريا والامونيا والكميات المستخدمة من النواتج الثانوية الزراعية بمحافظة

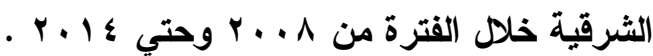

\begin{tabular}{|c|c|c|c|c|c|c|c|c|c|c|}
\hline \multicolumn{2}{|c|}{ المعاملة باليوريا } & \multicolumn{2}{|c|}{ معاملة بالامونيا } & \multicolumn{2}{|c|}{ فرم مخلفات } & \multicolumn{2}{|c|}{ كومات سمادية } & \multicolumn{2}{|c|}{ عمل سيلاج } & \multirow{3}{*}{ السنو ات } \\
\hline الكمية & عدد & الكمية & عدد & الكمية & عدد & الكمية & عدد & الكمية & عدد & \\
\hline بالطن & المز ارعين & بالطن & المزارعين & بالطن & المز ار عين & بالطن & المزارعين & بالطن & المز ارعين & \\
\hline 4867 & 3906 & 660 & 66 & 190090 & 38358 & 45372 & 4964 & 3651 & 607 & 2008 \\
\hline 4323 & 3779 & 470 & 47 & 77232 & 15585 & 37500 & 3803 & 2794 & 415 & 2009 \\
\hline 2312 & 1375 & 320 & 32 & 51558 & 10404 & 20036 & 1752 & 3214 & 536 & 2010 \\
\hline 3000 & 1721 & 30 & 3 & 95020 & 19174 & 22500 & 4632 & 2845 & 463 & 2011 \\
\hline 2317 & 1222 & 110 & 11 & 99410 & 20060 & 29800 & 5167 & 6435 & 1028 & 2012 \\
\hline 1111 & 649 & 21 & 2 & 100130 & 20205 & 29050 & 5862 & 5114 & 855 & 2013 \\
\hline 2634 & 1536 & 50 & 5 & 10800 & 2179 & 26595 & 5321 & 4301 & 744 & 2014 \\
\hline 2937.71 & 2026.86 & 237.28 & 23.71 & 89177.14 & 17995 & 30121.86 & 4500.14 & 4050.571 & 664 & المنوسط \\
\hline 1186.29 & 1189.65 & 233.21 & 23.33 & 50910.4 & 10273.18 & 8110.95 & 1267.39 & 1240.45 & 206.12 & الانحر افالمعياري \\
\hline 40.38 & 58.69 & 98.28 & 98.39 & 57.09 & 57.09 & 26.93 & 28.16 & 30.62 & 31.04 & الاختلاف معامل \\
\hline-16 & -23 & -53.6 & -54 & -26.7 & -27 & -6.1 & 7.7 & 8.6 & 9.7 & معدل النمو (\%) \\
\hline
\end{tabular}


ثانيا : العوامل المؤثرة علي انتاج السيلاج وقش الارز المعالج بالامونيا واليوريا : ا

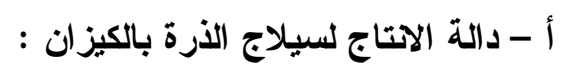

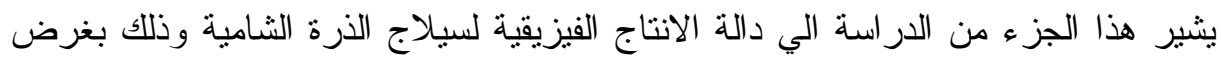
معرفة اكثر العناصر الانتاجية أهمية ( أكثر إيجابية ) في إنتاج السيلاج ليتم الاهتمام بهذه العناصر

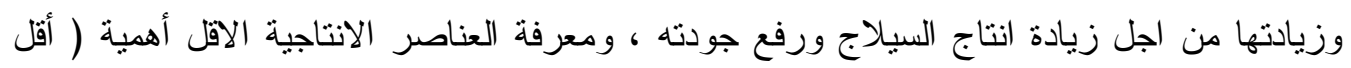
إيجابية إي سلبية ) في انتاج السيلاج ومحاولة نقليلها من اجل تخفيض التكاليف الخاصة بعملية انتاج

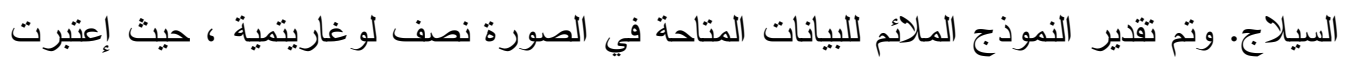

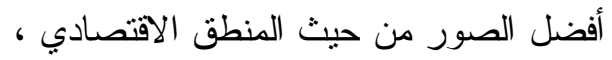

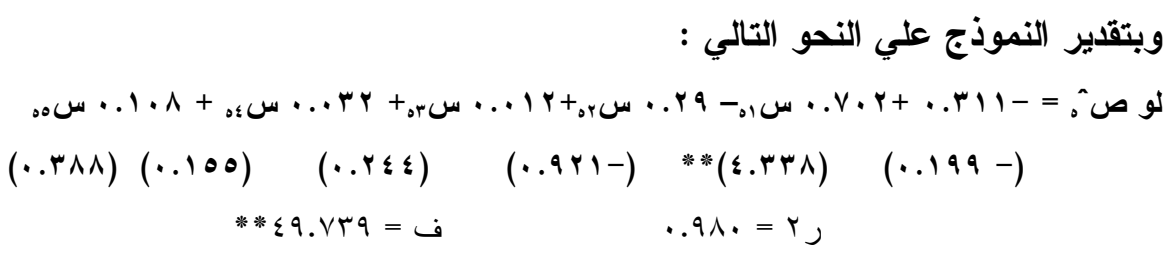

حيث أن : ص ^ هـ = كمية السيلاج المنتج (المقدر) بالطن من محصول الذرة الثامية في المشاهدة

سا, هـ = كمية عيدان الذرة الثامية بالكيزان المفرومة بالطن في المشاهدة هـ ـ همان.

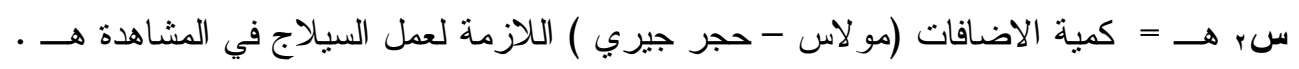

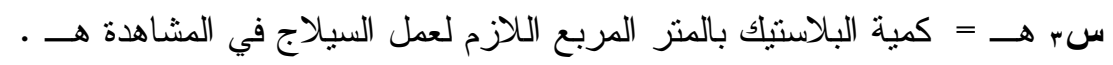

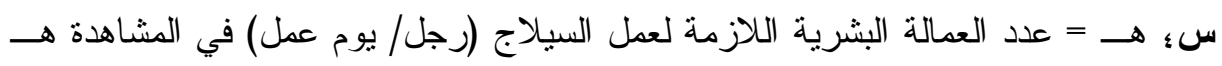

سه. هـ = عدد العمل الآلي بالساعة اللازم لعمل السيلاج في المشاهدة هـ .

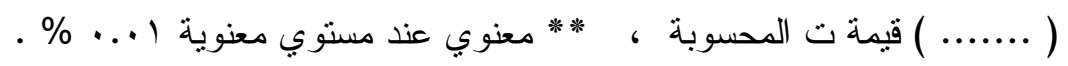

المصدر : جمعت وحسبت من بيانات عينة الدراسة الميدانية بمحافظة الثرقية .

تشير نتائج الدالة إلي أنه يوجد علاقة طردية موجبة معنوية احصائيا بين كل من كمية السيلاج المنتج (المقدر) بالطن وكمية عبدان الذرة الثامية بالطن ، وهذا يتفق مع المنطق الاقتصادي مئه

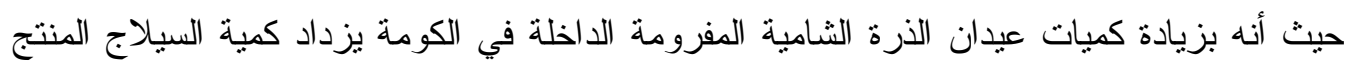
• بينما اوضح النموذج وجود علاقة عكسية غير معنوية احصائيا عند المسنوي الاحتمالي (

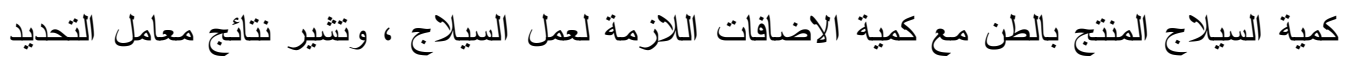

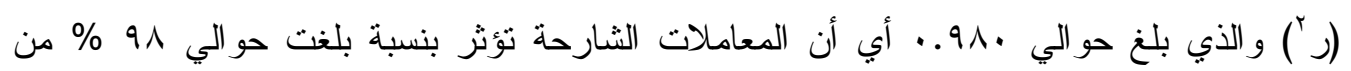

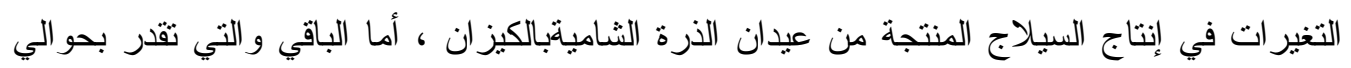

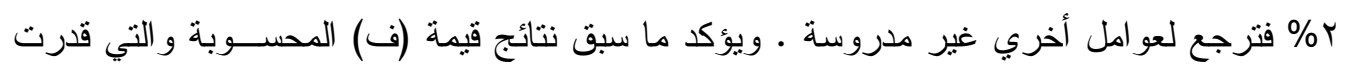

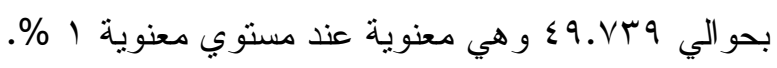


ب - تكاليف تصنيع السيلاج :

يشير الجدول رقم (V) تكاليف نصنيع طن منسيلاج الذرة الثامية بالكيزان بأن التكاليف

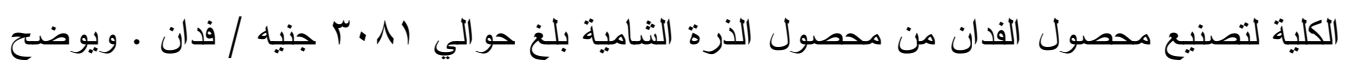

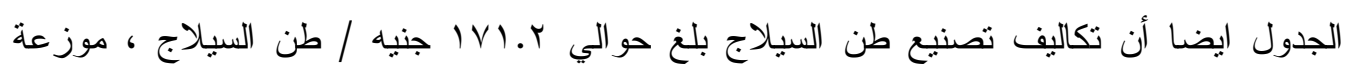

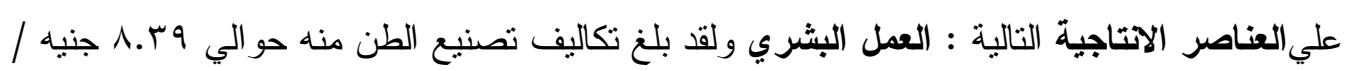

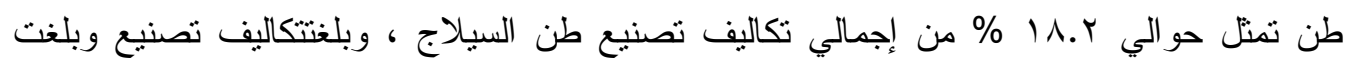

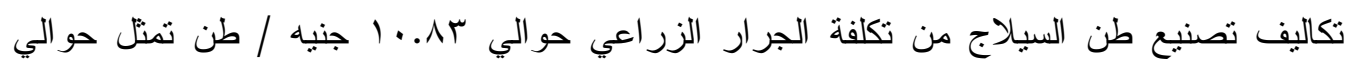
ع.r \% م من إجمالي تكاليف تصنيع طن السيلاج ، وبلغت تكاليف تصنيع طن السيلاج منأجور

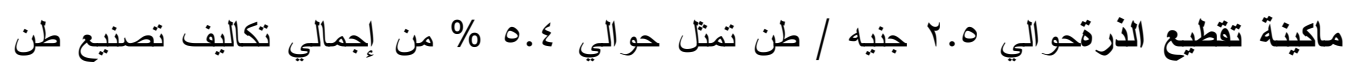

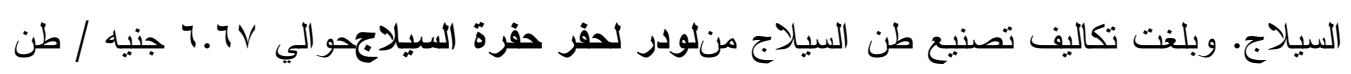

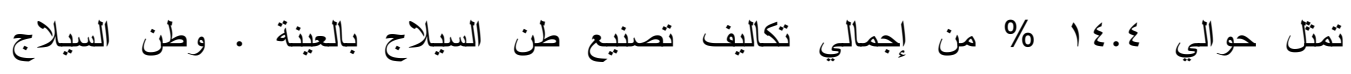

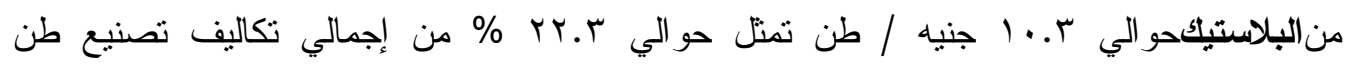

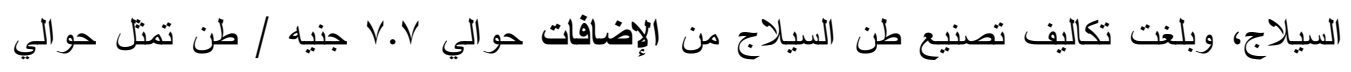
r.17 \% من إجمالي تكاليف تصنيع طن السيلاج .

جدول رقم (V): تكاليف تصنيع طن سيلاج الذرة الثامية بالكيزان بمحافظة الشرقية عام ؛ ا ـ ؟.

\begin{tabular}{|c|c|c|c|}
\hline \% من تكاليف & تكاليف تصنيع الطن & تكاليف تصنيع & و عناصر التكاليف \\
\hline IN.Y & N.rq & 101 & العمل البشري \\
\hline r.T.T & $1 . . r$ & 110 & البلاستيك \\
\hline 17.5 & V.V & 1 To & الاضافات (مو لاس+حجر جيري) \\
\hline rT.\& & $1 . . \wedge r$ & 190 & تكلفة الجر ار \\
\hline $0 . \varepsilon$ & r... & «o & أجور ماكينة تقطيع الذرة \\
\hline $1 \leq . \varepsilon$ & $7.7 \mathrm{~V}$ & ir. & لودر لحفر الحفرة للسيلاج \\
\hline-- & ro & rro. & ثمن محصول الذرة الثشامية بالكيز ان \\
\hline-- & 171.19 & $r \cdot \Lambda)$ & إجمالي التكاليف \\
\hline
\end{tabular}

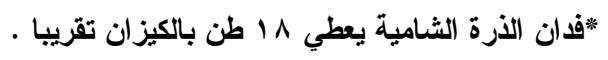

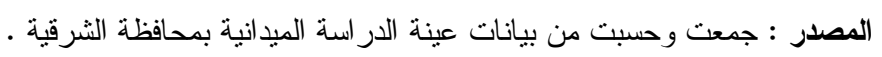

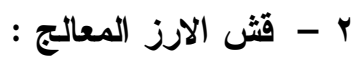

أ - دالة الاتتاج لقش الارز : توضح الدر اسة الهية دوال الانتاج الفيزيقية لقش الارز المعالج وذلك الكي بغرض معرفة اكثر العناصر الانتاجية أهمية ( أكثر إيجابية ) في إنتاج الكومات ليتم الاهنمام بهذه 
العناصر وزيادتها من اجل زيادة انتاج الكومات ورفع جودته ، ومعرفة العناصر الانتاجية الاقل

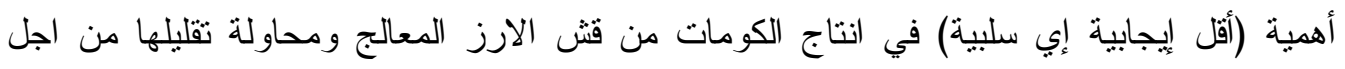
تخفيض التكاليف الخاصة بعملية انتاج هذه الكومات ـ ونم تقدير النموذج الملائم للبيانات المتاحة في الصورة نصف لوغاريتمية ، حيث إعتبرت أفضل الصور من حيث المنطق الاقتصادي، ويتقدير النموذج علي النحو التالي : لو صٌ هـ = -

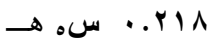

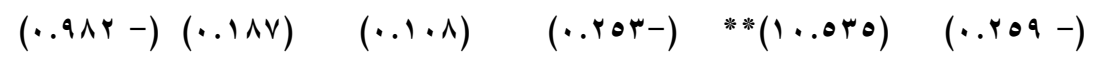

$$
\begin{aligned}
& \text { **NA.110 = ف } \\
& \text { حيث أن : ص ^ هـ = كمية قش الارز المعالج بالطن لمحصول الارز في المشاهدة هـ. } \\
& \text { سا هـ = كمية قش الارز بالطن في المشاهدة هـ . } \\
& \text { سr هـ = كمية الاضافات اللازمة لعمل الكومة في المشاهدة هـ . } \\
& \text { سب هـ = كمية البلاستيك بالمتز المربع اللازم لعمل الكومة في المشاهدة هـ . }
\end{aligned}
$$

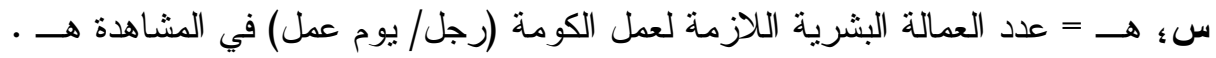

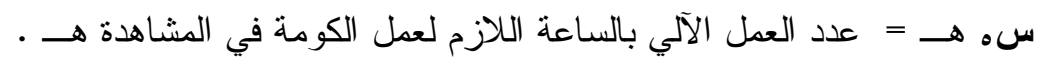

$$
\begin{aligned}
& \text { المصدر : جمعت وحسبت من بيانات عينة الدراسة الميدانية بمحافظة الثرقية . }
\end{aligned}
$$

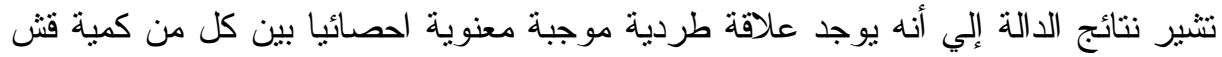
الارز بالطن وكمية قش الارز المعالجبالطن ، وهذا ينتشي مع المنطق الاقتصادي حيث أنه بزيادة

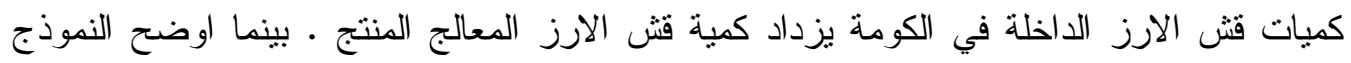
وجود علاقة عكسية غير معنوية احصائيا عند المستوي الاحتمالي ا ( ب بين كمية فش الارز المنتج

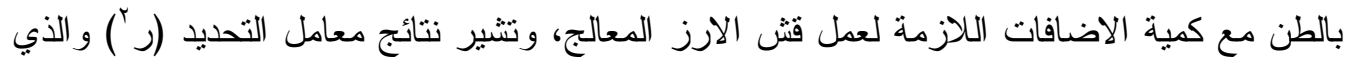

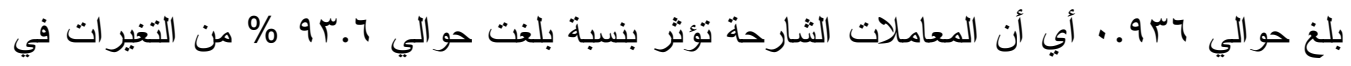

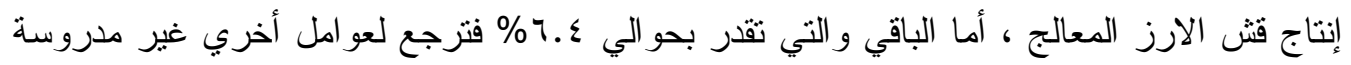

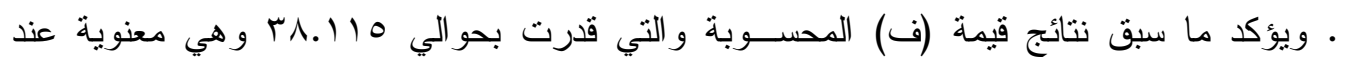

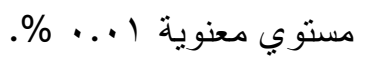

ب - تكاليف تصنيع قش الارز المعالج :

يشير الجدول رقم (^) تكاليف تصنيع طن من قش الارز المعالج بأن التكاليف الكلية

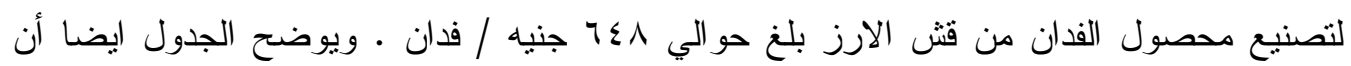

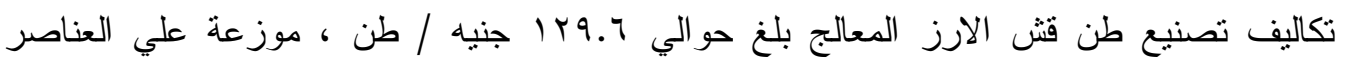

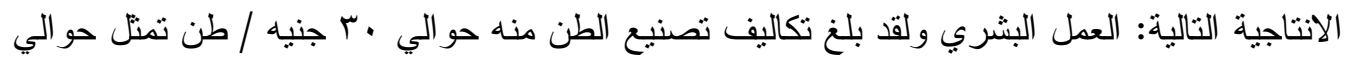
r.r r r من إجمالي تكاليف تصنيع الطن ، وتكاليف تصنيع طن القش المعالج من عنصر البلاستيك

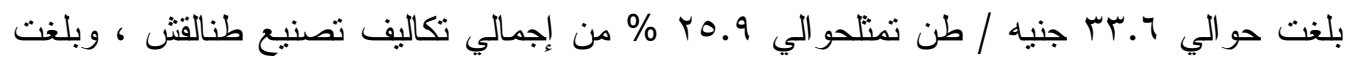

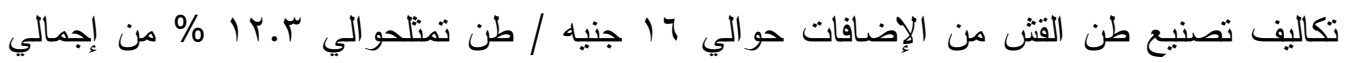
تكاليف تصنيع طن . ت ن 
جدول رقم (^) : تكاليف تصنيع طن من قش الارز المعالج بعينة الدراسة الميدانية بمحافظة

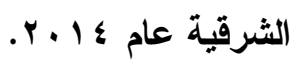

\begin{tabular}{|c|c|c|c|c|c|c|}
\hline التكاليف الكلية & تكلفة & بالجنيه & سعر الوحدة & كمية & & البنود \\
\hline ro.9 & T. & 171 & $\wedge$ & Y) & & بلاستيك مr \\
\hline rT.t & r. & 10. & 0. & r & (رجل & العمل البشري \\
\hline rᄉ. & 0. & ro. & 0 . & 0 & & (يوم) \\
\hline IT.r & 17 & $\wedge$. & r & $\varepsilon$. & & اليوريا بالكجم بالطن \\
\hline $1 \cdots$ & $1 Y 9.7$ & $T \leqslant \wedge$ & -- & -- & & الإجمالي \\
\hline
\end{tabular}

المصدر : جمعت وحسبت من بيانات عينة الدر اسة الميدانية بمحافظة الثرقية .

تشير نتائج جدول رقم (9) نتائج تحليل التباين لتكلفة تصنيع السيلاج وقش الارز المعالج

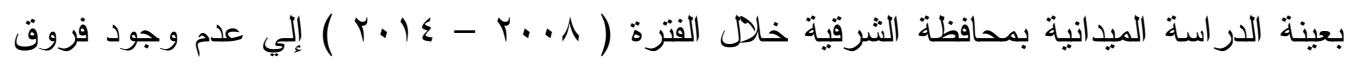
معنوية إحصائية بين كل من تكلفة التصنيع للطن بالجنيه من جانب وكذلك عدم وجود فروق معنوية

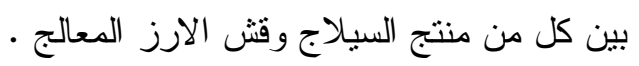

جدول رقم (9) : نتائج تحليل التباين لتكلفة تصنيع السيلاج وقش الارز المعالج بعينة الدراسة

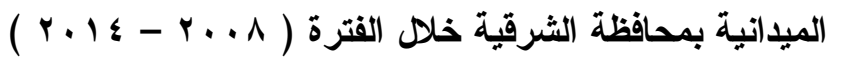

\begin{tabular}{|c|c|c|c|c|c|}
\hline $\mathrm{Ft}$ & $\mathrm{F} \mathrm{C}$ & متوسط المربعات & $\begin{array}{c}\text { درجات الحرية } \\
\text { d f }\end{array}$ & مجموع المربعات & $\begin{array}{c}\text { مصدر التباين } \\
\text { S V }\end{array}$ \\
\hline 7.19 & r.01 & r)T.Ir & $\varepsilon$ & A $\leqslant$ Or.OY & بين الصفوف \\
\hline \multirow[t]{3}{*}{$v . v 1$} & $\cdots r$ & $18 \cdot .9$. & 1 & $1 v \cdot .9$. & بين الاعمدة \\
\hline & & $\Lambda \varepsilon r . . r$ & $\varepsilon$ & rrVt.. 9 & الخطأ العشو ائي \\
\hline & & & 9 & 11990.01 & الخطأ الكلي \\
\hline
\end{tabular}

المصدر : جمعت وحسبت من بيانات عينة الدر اسة الميدانية بمحافظة الثرقية .

إت : مشاكل إنتاج السيلاج وقش الارز المعالج بالآمونيا واليوريا ثالث

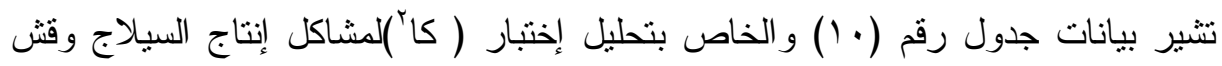

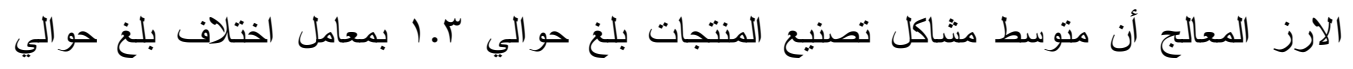

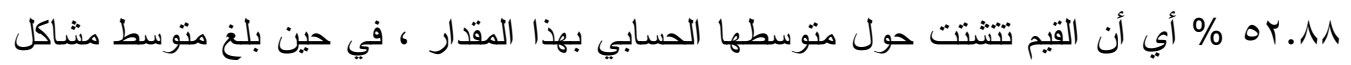

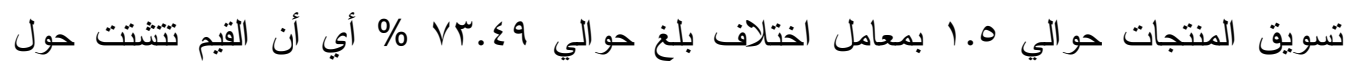


منوسطها الحسابي بهذا المقدار ، و أخير ا بلغ منوسط مشاكل الاعلاف التقليدية حوالي 1.9 بمعامل

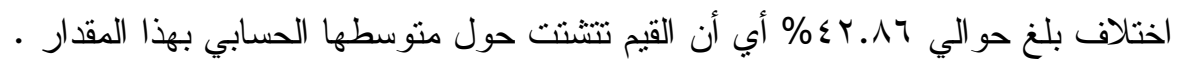

جدول رقم ( • 1) : التحليل الاحصائي لمشاكل إنتاج السيلاج وقش الارز المعالج بإستخدام ( كا؟)

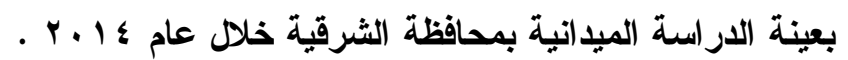

\begin{tabular}{|c|c|c|c|c|}
\hline اعلي قيمة & معامل الاختلاف & الانحر اف المعياري & $\begin{array}{c}\text { المتوسط } \\
\text {-X } \\
\end{array}$ & إجمالي مشاكل \\
\hline r & 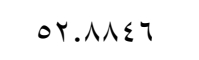 &.$v .011$ & אזrא.1 & تصنيع المنتجات \\
\hline$\varepsilon$ & 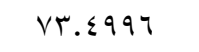 & 1.1 1 998 & אזror & نسويق المنتجات \\
\hline r & SY.人TTY & $. \wedge \leqslant r .0$ & $1.977 \mathrm{~V}$ & الاعلاف النقلبدية \\
\hline
\end{tabular}

المصدر : جمعت وحسبت من بيانات عينة الدر لسة الميدانية بمحافظة الثرقية .

تشير بيانات جدول رقم (1) و الخاصة بنتائج اختبار مربع كاي إلي وجود نأثير مشترك

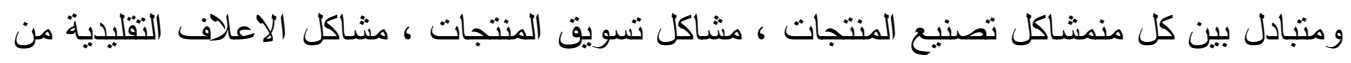

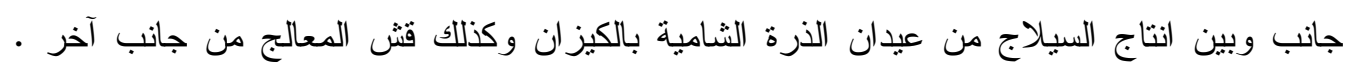
كذلك يتضح من نتائج اخنبار مربع كابي إلي وجود فروق معنوية بين مشاكل تصنيع المنتجات ،

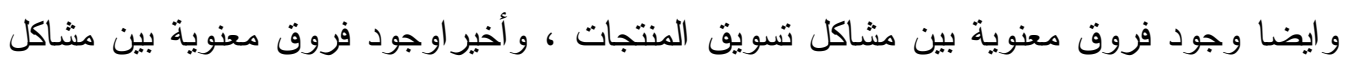

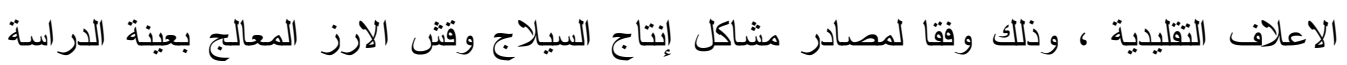

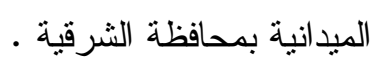
جدول رقم (1') : نتائج تحليل كا` لمشاكل إنتاج السيلاج وقش الارز المعالج بعينة الدراسة الميدانية

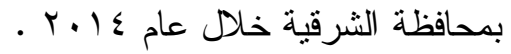

\begin{tabular}{|c|c|c|c|}
\hline مشاكل الاعلاف التقليدية & مشاكل تسويق المنتجات & مشاكل تصنيع المنتجات & البيان البيان \\
\hline אמש.VI & $1 \leq .77 \mathrm{~V}$ & r & كا' \\
\hline$r$ & $\varepsilon$ & $r$ & درجات الحرية \\
\hline$\ldots \ldots$ & $\ldots \ldots$ & $\cdots \cdots$ & المعنوية \\
\hline
\end{tabular}

المصدر : جمعت وحسبت من بيانات عينة الدر اسة الميدانية بمحافظة الثرقية .

رابعا:مقترحات تطوير وتحديث نشاط إنتاج السيلاج وقش الارز المعالج بالآمونيا واليوريا

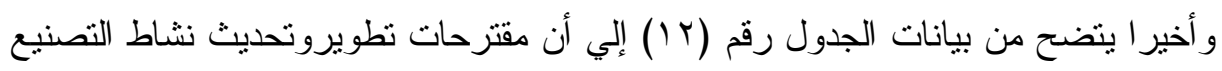

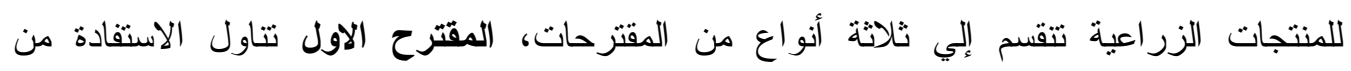

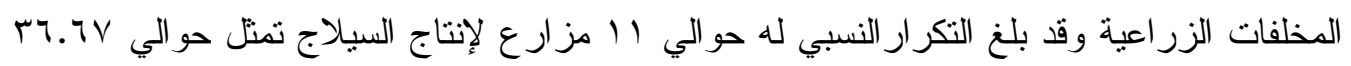

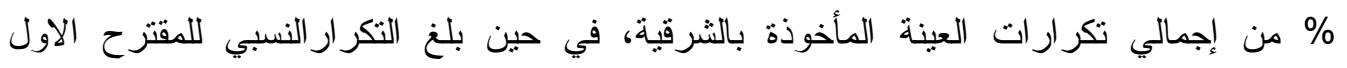

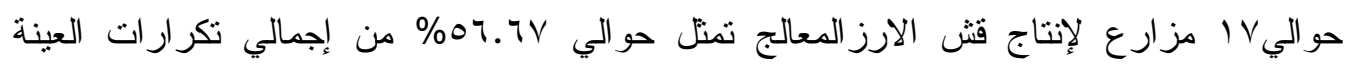
المأخوذة . 
جدول رقم (r Y) :الاهمية النسبية لمقترحات تطوير وتحديث نشاط إنتاج السيلاج وقش الارز

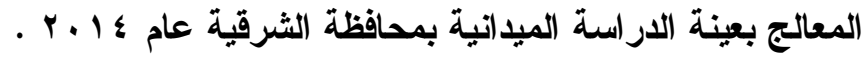

\begin{tabular}{|c|c|c|}
\hline \multicolumn{2}{|c|}{ الاهمية النسبية (\%) } & \multirow{2}{*}{ المقترح } \\
\hline قش الارز المعالج & 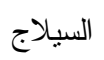 & \\
\hline $07.7 \mathrm{~V}$ & M..7V & الاستفادة من المخلفات الزر اعية \\
\hline (r.r & $17.7 \mathrm{~V}$ & وجود علف بالمزرعة \\
\hline r..TV & M..TV & عدم شر اء علف مصنع مرتفع السعر \\
\hline T.r & 9.99 & أخري \\
\hline $1 \ldots$ & $1 .$. & الاجمالي \\
\hline
\end{tabular}

المصدر : جمعت وحسبت من بيانات عينة الدر اسة الميدانية بمحافظة الثرقية .

المقترح الثاني تتاول وجود علف بالمزرعة وقد بلغ النكر ارالنسبي له حو الي ه مز ارعين لإنتاج السيلاج تمنل حوالي VI7.7 \% من إجمالي تكرارات العينة المأخوذة بالثرقية، في حين بلغ

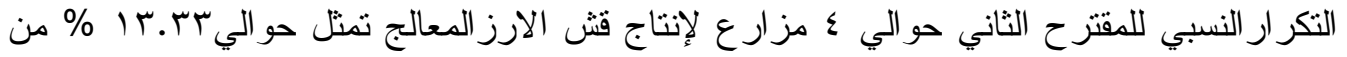
إجمالي نكر ار ات العينة المأخوذة ـ المقترح الثالث تتاول عدم شر اء علف مصنع مرتفع السعروقدبلغ

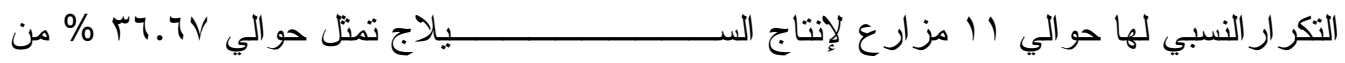
إجمالي تكرارات العينة المأخوذة بالثرقية، في حين بلغ التكرار النسبي للمقترح الثالث حواليى

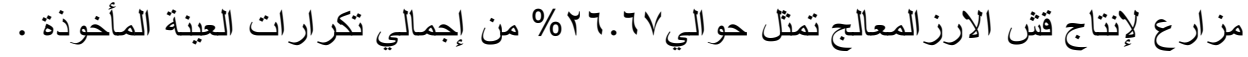

\section{ملخص الاراسة}

يعتبر نقص المو اد العلفية من المعوقات الاساسية لتتمية وتطوير الانتاج الحيو اني ، وتتشير العديد من

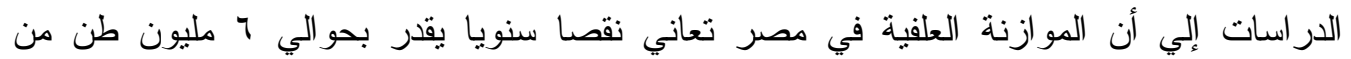
الاعلاف إي حوالي ه.ب مليون طن من المواد العلفية المهضومة ، وحيث أن توفر الموارد العلفية ضرورة حتمية فإن أفضل وسيلة لتحقيق هذا الهدف هو عمل خطة للإستفادة من المواد الغذائية الموجودة في المخلفات الزراعية والتي يمكن الاستفادة منها كأعلاف حيوانية ومن أهمها الاتبان و أحطاب الذرة و القطن وكنللك قش الارز وعروش الخضروات ، وتثير الدراسات أن هذه الكميات

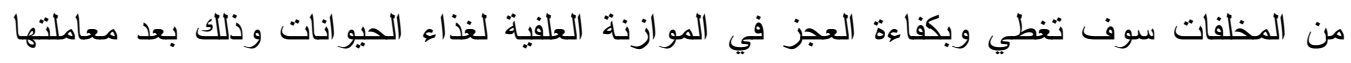
ميكانيكيا أو طبيعيا أو كيميائيا أو بيولوجيا لرفع قيمتها الغذائية ثم إستخدامها كأحد مكونات الاعلاف فئه

$$
\text { الحيو انية . مئر }
$$

وتتلخص مشكله الاراسة في أن هناك نقص في إستخدام كميات المخلفات الزراعية لتحويلها إلي أعلاف غير تقليدية حتي بلغت الكميات المستخدمة هي 0.0 مليون طن من فن إجمالي

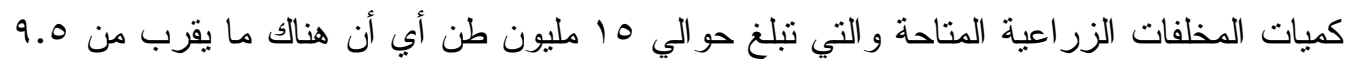
مليون طن مخلفات زر اعية غير مستخدمة في التدوير إلي أعلاف غير تقليدية لسد الفجوة العلفية . 
وتهدف الاراسة الي زيادة إستخدام الاعلاف غير التقليدية و إدخالها في برامج التغذية

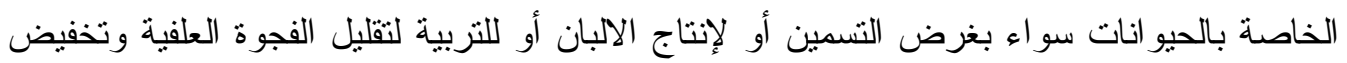

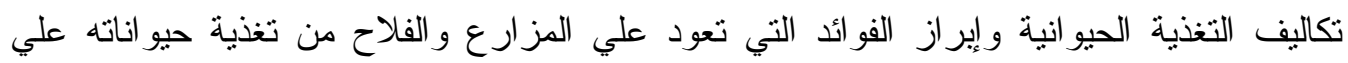

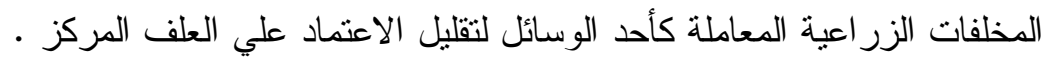

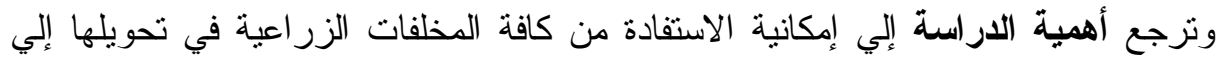
أعلاف غير تقليدية يمكن أن تحل محل جزء كبير من الاعلاف المركزة الغالية الثمن و المكلفة جدا لـاعه بالنسبة للمزار عين وذللك بأقل التكاليف الممكنة مما يساهم في سد الفجوة العلفية .

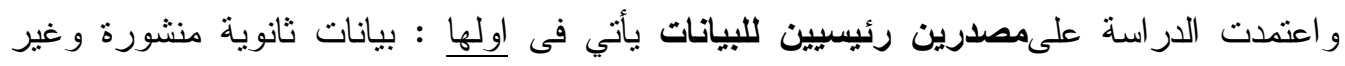

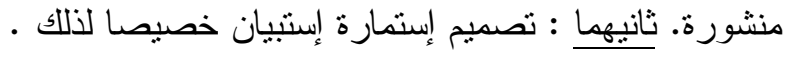

\section{وتوصلت الدراسة إلي العديد من النتائج منها :}

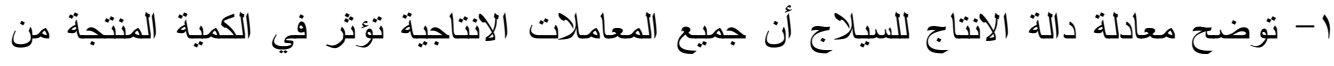

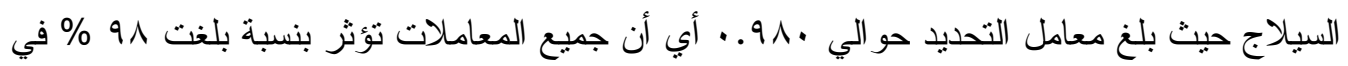

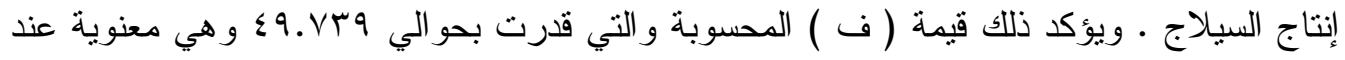

$$
\text { مستوي معنوية ا ل... }
$$

ץ- توضح معادلة دالة الانتاج لقش الارز المعالج أن جميع المعاملات الانتاجية تؤثر في الكمية

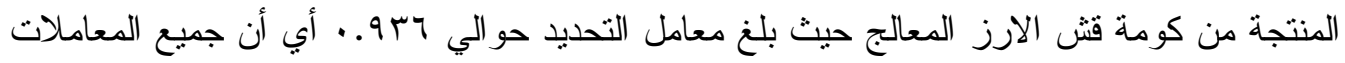

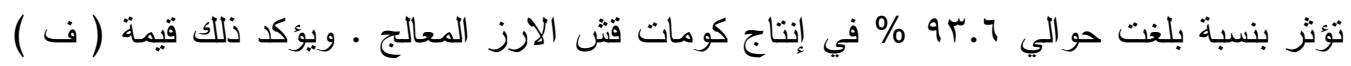

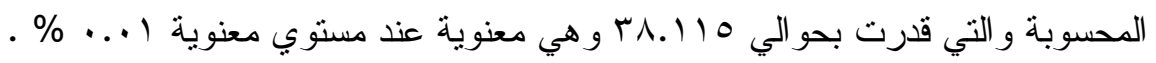

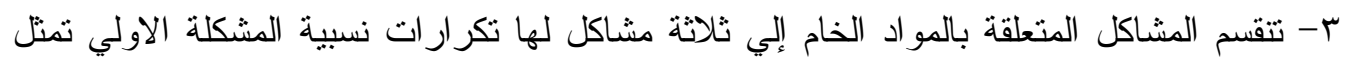

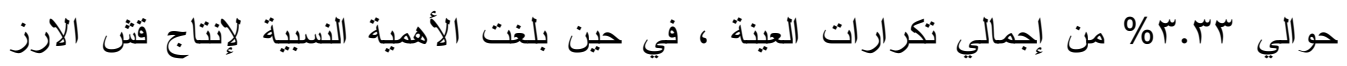

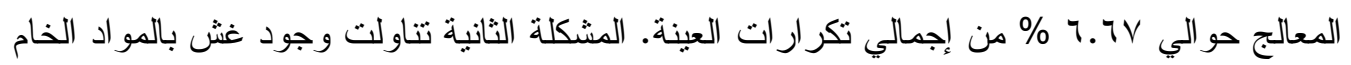

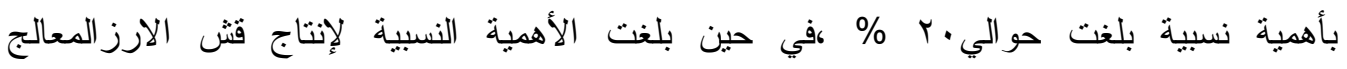

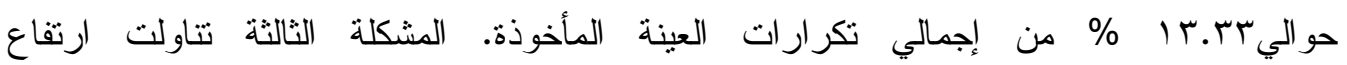

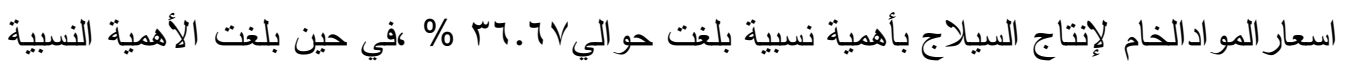

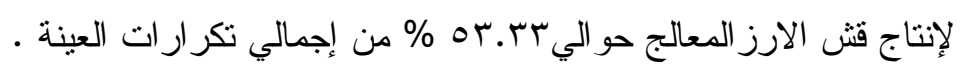
ع- تتقسم مقترحات تطوير و تحديث نشاط التصنيع للمنتجات الزر اعية إلي ثلاثة مقترحات، المقتر ح

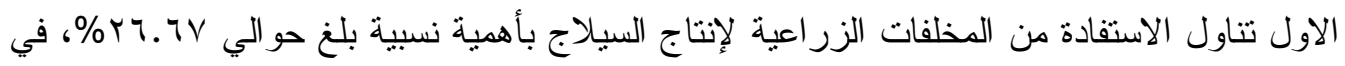

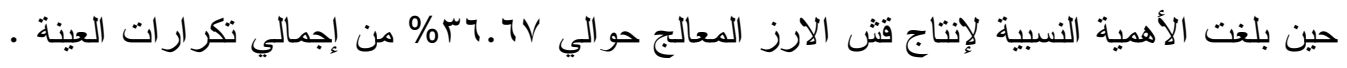

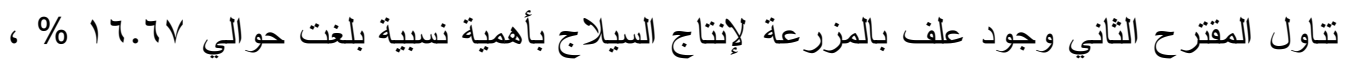

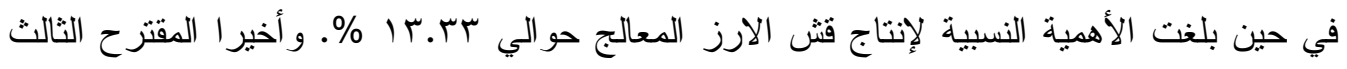

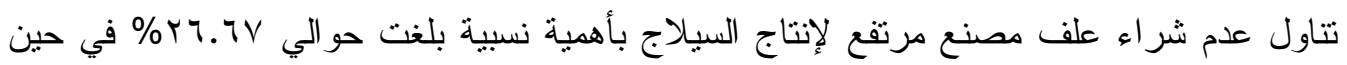

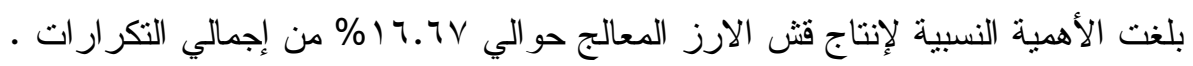




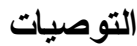 \\ في ضوء ما سبق فإن الار اسة توصي بما يلي :}

تعد الاعلاف من أهم العوامل المحددة لإنتاج اللحوم و الالبان في مصر لذان لذا لابد من التركيز

علي محتو اها الغذائي بشكل عام و المكونات العلفية بشكل خاص .

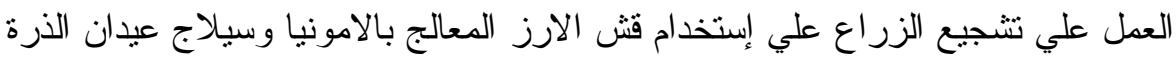

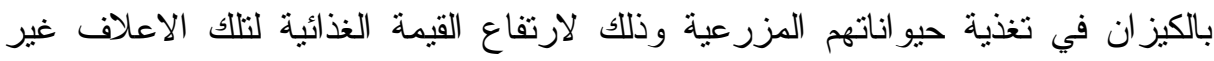

يجب التوسع في نشر تكنولوجيا تدوير المخلفات النباتية وذللك بزيادة القيمة المضافة لهذه

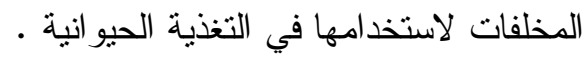

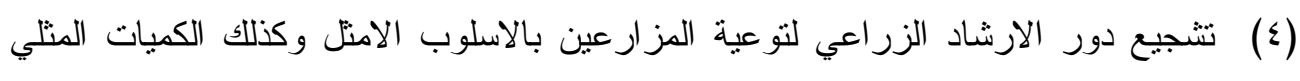

المقدمة للحيو انات من الاعلاف غير التقليدية .

المراجع

1 - حسن بيومي سمور وآخرون : دراسة اقتصادية وفنية لأثر إستخدام بعض الحزم الغذائية في

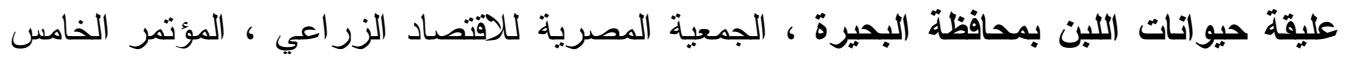

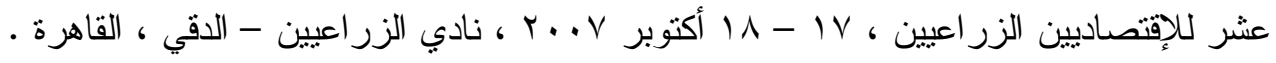

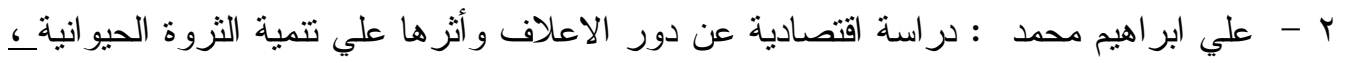

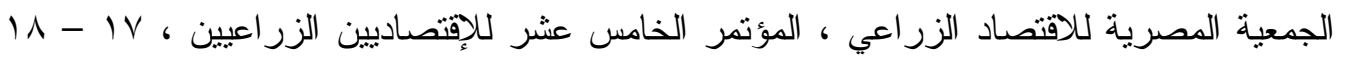

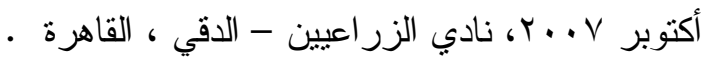
r - علاء الدين أحمد الطحان ، محمد عبد الخالق الصاوي : : دراسة القتصادية لتغذية ماثنية اللبن علي سيلاج الذرة بمحافظة الغربية ، الجمعية المصرية للاقتصاد الزراعي ، المؤتمر الثالث

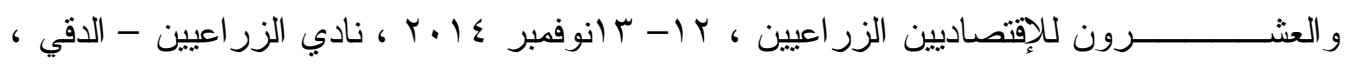

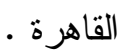
ع كوزارة الزر اعة ، قطاع الشئون الاقتصادية ، معهد بحوث الانتاج الحيو اني ، قسم بحوث التغذية

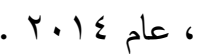
ه - وزارة الزر اعة ، مديرية الزراعة بالشرقية ، سجلات رسمية ، بيانات غير منشورة ، سنوات مختلفة . - م 1 - محافظة الثرقية ، مركز المعلومات ودعم اتخاذ القرار ، سجلات رسمية ، بيانات غير منشورة ، سنوات مختلفة . 


\title{
AN ECONOMIC STUDY FOR UNTRADITIONAL FODDER AND THE ITS ROLE TO FIX FODDER SHORTAGE IN SHARKIA GOVERNORATE
}

\author{
ABD-ELFATTAH, A.E., A.A.A. NEMA and M.E.M.RAFAT \\ Agri, Econ, Resh, Instit. Agri, Reash, Center.
}

(Manuscript received 6 April 2016)

\begin{abstract}
$\mathrm{F}$ odder shortage is considered an impediment to develop animal production, many studies show that fodder balance in Egypt has a 6 million ton annual shortage and that equal 2.5 million ton of digested fodder, the availability of the fodder is a necessity and the best way to achieve that is making a plan to benefit from the nutrition which existed in agricultural waste and it can be used as an animal fodder where the most important are ; hays, corn wood, cotton, rice straw and vegetable forks, many studies show that this quantities of agricultural waste will cover efficiently the shortage of fodder balance to feed the animals and that after treating them with mechanical, natural , chemical and biological processes to raise their nutritional value then using them as an animal fodder materials .
\end{abstract}

The results obtained are summarized as follows:

1-The equation of production function shows that all productive treatments affect produced silage because The coefficient of determination is about 0.980 which means that all treatment affect with percentage reached $98 \%$ in silage production, calculated (F) value confirms that which reached 49.739 with abstract level 0.01 $\%$.

2-The equation of processed rice straw production function shows that all treatments affect the produced quantity of rice straw pile with coefficient of determination reached 0.936 which means that all treatments affect the processed rice straw pile with percentage of $93.6 \%$, the value of calculated (F) confirms that and reached 38.115 with coefficient of determination $0.01 \%$.

3-The problems of raw materials vary to three problems have relative recurrences, the first problem with relative importance reached $3.33 \%$ of all recurrences, when the relative importance of processed rice straw reached $6.67 \%$ of all recurrences . the second problem is about raw materials deception which reached about $20 \%$, when the relative importance of processed rice straw reached $13.33 \%$ of all recurrences . the third problem is about price raising of raw materials to produce silage with relative importance reached $36.67 \%$, when the relative importance to produce the processed rice straw reached $53.33 \%$ of all sample recurrences .

\section{Recommendations :}

1- Fodders are an important coefficient of determination in the meat and milk production in Egypt .

2- Encouraging the farmers to use rice straw treated with ammonia and corn forks silage to feed their farm animals .

3- Expansion of using agricultural waste recycling technology by raising the added value to that waste to use it in animal feeding .

4- Encouraging the role of agricultural extention to aware the farmers about optimum way and the optimum quantities of untraditional fodder presented to the animals . 